\title{
HETEROGENEOUS INFORMATION ARRIVALS AND RETURN VOLATILITY DYNAMICS: UNCOVERING THE LONG-RUN IN HIGH FREQUENCY RETURNS
}

\author{
Torben G. Andersen \\ Tim Bollerslev
}

Working Paper 5752

\section{NATIONAL BUREAU OF ECONOMIC RESEARCH 1050 Massachusetts Avenue Cambridge, MA 02138 \\ September 1996}

We gratefully acknowledge the financial support provided by a research grant from the Institute for Quantitative Research in Finance (the Q-Group). We would also like to thank Olsen and Associates for providing the intradaily exchange rates and Reuter's news tape analyzed in the paper. This paper is part of NBER's research program in Asset Pricing. Any opinions expressed are those of the authors and not those of the National Bureau of Economic Research.

(C) 1996 by Torben G. Andersen and Tim Bollerslev. All rights reserved. Short sections of text, not to exceed two paragraphs, may be quoted without explicit permission provided that full credit, including $(\mathrm{C}$ notice, is given to the source. 


\title{
HETEROGENEOUS INFORMATION ARRIVALS AND RETURN VOLATILITY DYNAMICS: UNCOVERING THE LONG-RUN IN HIGH \\ FREQUENCY RETURNS
}

\begin{abstract}
Recent empirical evidence suggests that the long-run dependence in financial market volatility is best characterized by a slowly mean-reverting fractionally integrated process. At the same time, much shorter-lived volatility dependencies are typically observed with high-frequency intradaily returns. This paper draws on the information arrival, or mixture-of-distributions hypothesis interpretation of the latent volatility process in rationalizing this behavior. By interpreting the overall volatility as the manifestation of numerous heterogeneous information arrivals, sudden bursts of volatility typically will have both short-run and long-run components. Over intradaily frequencies, the short-run decay stands out most clearly, while the impact of the highly persistent processes will be dominant over longer horizons. These ideas are confirmed by our empirical analysis of a one-year time series of intradaily five-minute Deutschemark - U.S. Dollar returns. Whereas traditional time series based measures for the temporal dependencies in the absolute returns give rise to very conflicting results across different intradaily sampling frequencies, the corresponding semiparametric estimates for the order of fractional integration remain remarkably stable. Similarly, the autocorrelogram for the low-pass filtered absolute returns, obtained by annihilating periods in excess of one day, exhibit a striking hyperbolic rate of decay.
\end{abstract}

Torben G. Andersen

Department of Finance

J.L. Kellogg Graduate School of Management Northwestern University

2003 Sheridan Road

Evanston, IL 60208

t-andersen@nwu.edu
Tim Bollerslev

Department of Economics

Rouss Hall

University of Virginia

Charlottesville, VA 22903

and NBER

bollerslev@virginia.edu 


\begin{abstract}
"Among the most puzzling issues is the behavior of volatility. While the general properies of volatility remain elusive, perhaps the most intriguing feature revealed by empirical work on volatility is its long persistence. Such behavior has sparked a search, almost akin to that for the Holy Grail, for the perfect GARCH model, but the underlying question of why such volatility persistence endures remains unanswered. We conjecture that the ability to analyze higher frequency data may be particularly useful in pursuing this issue." (Goodhart and O'Hara (1996))
\end{abstract}

\title{
1. INTRODUCTION
}

A large body of literature seeking to characterize the long-run dependencies in the interdaily volatility of speculative returns has emerged over the past decade. ${ }^{1}$ More recently, there has been an explosicn in the amount of empirical research devoted to the determination of high frequency intradaily return volatility dynamics. ${ }^{2}$ Unfortunately, the empirical estimates pertaining to the degree of volatility persistence reported in these two strands of the literature often appear at odds with one another. While studies using daily or lower frequency returns generally point to a very high degree of intertemporal volatility dependence, the estimated half-lives of most identifiable intraday volatility shocks seem rather low, with any noticeable effects on the overall volatility level typically gone in a matter of hours or less. The analysis in the present paper provides a theoretical justification for these seemingly contradictory findings. By interpreting the overall volatility as the aggregation of numerous independent volatility components, each endowed with their own dependence structure, we show how the aggregate volatility process may inherit the kind of long-run dependencies associated with long-memory, or fractionally integrated processes. Consequently, the autocorrelations for more distantly spaced absolute or squared returns, should exhibit a slow hyperbolic rate of decay, independent of the sampling frequency.

This mixture-of-distributions hypothesis interpretation of market volatility as resulting from the aggregation of numerous components type processes apply equally well across most financial markets and instruments. However, for concreteness the empirical analysis in the paper is focussed on the foreign exchange market, and a one-year time span of 5-minute Deutschemark - U.S. Dollar (DM-\$) returns. Consistent with the notion of an underlying component structure, we find that the dynamic response of the absolute 5-minute foreign exchange returns varies systematically across

\footnotetext{
1 See Bollerslev, Chou and Kroner (1992) for a survey of this literature using ARCH type models.

2 For a recent survey of this literature see Goodhart and O'Hara (1996).
} 
some of the most important and readily identifiable macroeconomic announcements. Furthermore, the volatility process is shown to exhibit the kind of long-memory dependencies implied by the theoretical aggregation of such multiple individual component processes. This interpretation of volatility is further underscored by the fact that the corresponding estimates for the fractional orders of integration for the absolute returns remain remarkably stable across all of the intradaily sampling frequencies.

Although these empirical findings consistently point to the presence of long-memory, the pronounced intradaily volatility patterns, known to exist in most financial markets, severely complicate any further direct analysis of the long-run volatility dependencies. However, by low-pass filtering the absolute intradaily returns, thus annihilating any cyclical behavior with a periodicity of less than one day, we demonstrate how it is possible to uncover the salient long-run volatility dynamics using standard correlation based measures. Specifically, whereas the autocorrelogram for the raw absolute intradaily returns periodically turn negative, the autocorrelogram for the low-pass filtered absolute intradaily returns display a striking hyperbolic rate of decay. Consequently, these filtered returns constitute an ideal basis for more comprehensive analyses of the important volatility determinants, as illustrated by our estimation of the announcement effects associated with the regularly scheduled release of different macroeconomic "news".

The plan for the remainder of the paper is as follows. Section 2 briefly reviews some of the existing literature on the intradaily dependencies in the foreign exchange market. This section also presents preliminary estimation results for specific announcement effects that point to the existence of multiple volatility components and long-run dependencies. The mixture-of-distributions hypothesis and the temporal aggregation argument are presented in section 3, where we show that, under suitable assumptions concerning the underlying component structure, the spectrum for the overall volatility process implies an eventual slow hyperbolic rate of decay in the autocorrelations for the absolute returns, irrespective of the sampling frequency. The theoretical developments are validated by the empirical analysis in section 4 , which reports the results obtained from two alternative spectral-domain estimators for the degree of fractional integration in the volatility process across a range of different intradaily sampling frequencies. These findings are entirely consistent with the time-domain estimate for the fractional order of integration determined by the hyperbolic rate of decay in the autocorrelations for the low-pass filtered absolute returns presented in section 5 . This section also illustrates how the low-pass filtered absolute returns allow for important new insights 
into the structure behind the determination of the observed volatility. Section 6 concludes

\section{PRELIMINARY DATA ANALYSIS}

In order to motivate the subsequent theoretical developments, the following section describes the salient empirical features that pertain to the volatility in the DM- $\$$ foreign exchange market. However, the general ideas and empirical results apply equally well to other financial markets and high frequency return series; see, e.g., Andersen and Bollerslev (1996a) for a discussion of the parallels between the empirical properties of high frequency foreign exchange and equity index returns. The DM- $\$$ exchange rate data under study consist of all the quotes that appeared on the interbank Reuters network during the October 1, 1992 through September 29, 1993 sample period. The data were collected and provided by Olsen and Associates. Each quote contains a bid and an ask price along with the time to the nearest even second. The exchange rate corresponding to the endpoint of a given five-minute interval was determined as the interpolated average between the preceding and immediately following quotes weighted linearly by their inverse relative distance to this endpoint. The n'th five-minute return for day $\tau, \mathrm{R}_{r, \mathrm{n}}$, is then simply defined as the difference between the midpoint of the logarithmic bid and ask at the appropriately spaced time intervals. All 288 five-minute returns during the 24-hour daily trading cycle are used, but in order to avoid confounding the evidence by the decidedly slower trading patterns over the weekends, all returns from Friday 21:00 Greenwich Mean Time (GMT) through Sunday 21:00 GMT were excluded; see Bollerslev and Domowitz (1993) for a detailed analysis of the quote activity in the DM-\$ interbank market and a justification for this "weekend" definition. Similarly, to preserve the number of returns associated with one week we make no corrections for any worldwide or country specific Holidays that occurred during the sample period. All in all, this leaves us with a sample of 260 days, for a total of 74,880 5-minute intraday return observations; i.e., $R_{t}, t=1,2, \ldots, 74,880$, where $R_{(r-1) \cdot 288+}$ ${ }_{\mathrm{n}} \equiv \mathrm{R}_{\tau, \mathrm{n}}$, for $\mathrm{n}=1,2, \ldots, 288$, and $\tau=1,2, \ldots, 260$. For further discussion of the data construction we refer to Andersen and Bollerslev (1996a), where the same dataset has previously been analyzed from a different perspective.

Aside from the numerically small, but statistically significant, negative first order autocorrelation coefficient of -0.040 , the 5 -minute returns appear to be well approximated by a 
martingale process. ${ }^{3}$ However, the returns are clearly not independent, as the first order autocorrelation coefficient for $\left|R_{t}\right|$ equals 0.309. Also, the Ljung-Box statistic for up to tenth order serial correlation in the absolute returns takes a value of 36,680 , which is highly significant at virtually any level in the corresponding asymptotic chi-square distribution.

While the latter statistics are strongly suggestive of intraday volatility clustering, their overwhelming significance is in part attributable to the strong intradaily volatility pattern that is present in most financial markets. The importance of this phenomenon for the DM- $\$$ rates is obvious from figure 1, which graphs an estimate of the spectrum for the intradaily absolute 5-minute returns. ${ }^{4}$ The spectrum has a distinct peak at the daily frequency of approximately $2 \cdot \pi / 288 \approx$ 0.0218 , along with well defined peaks at the corresponding seasonal harmonics of $4 \cdot \pi / 288 \approx$ $0.0436,6 \cdot \pi / 288 \approx 0.0654,8 \cdot \pi / 288 \approx 0.0873$. This pronounced daily periodicity is also evident in the autocorrelogram for the absolute 5 -minute returns depicted out to a lag of 2,880 , or ten days, in figure 2. The intradaily pattern induces a distorted $U$-shape in the sample autocorrelations across each day, with the autocorrelations spaced half-a-day apart actually turning negative. The shape of the underlying intradaily volatility pattern over the 24-hour trading cycle in the foreign exchange market, and the close connection to the market activity in the various financial centers around the world, have previously been documented by Andersen and Bollerslev (1996a), Baillie and Bollerslev (1991), Dacorogna et al. (1993), Ito, Lyons and Melvin (1996), and Müller et al. (1990), among others. $^{5}$

Taken together, these results clearly point to the importance of appropriately accounting for the strong intradaily volatility patterns when analyzing high frequency dynamic dependencies, both

\footnotetext{
${ }^{3}$ The small negative autocorrelation may be explained by the asymmetric positioning of quotes by the foreign exchange dealers as a way to manage their inventory positions, thus causing the midpoint of the quoted prices to move around in a fashion analogous to the well documented bid-ask bounce effect on organized exchanges. This is also consistent with the results in Bollerslev and Domowitz (1993), who find similarly constructed 5-minute DM-\$ returns over a 3 months period in 1989 to be negatively correlated, while the first order autocorrelation for artificial constructed 5 -minute pseudo transactions price returns is actually positive. Similarly, the foreign exchange transactions prices analyzed by Goodhart, Ito and Payne (1995) show no negative correlation between subsequent returns.

4 The spectrum is estimated as the smoothed sample periodogram based on a triangular kernel with a bandwidth of ten: see, e.g., Hamilton (1994) or Priestley (1971). To allow for easier interpretation of the subsequent results, the plot is given on a double logarithmic scale.

5 Equally pronounced patterns have been documented for other financial markets, including the well known intradaily U-shape for equity market volatility; see e.g., Wood, McInish and Ord (1985) and Harris (1986).
} 
within and across different markets. However, even after explicitly modeling the typical intradaily patterns, several recent studies have found that the estimation of standard GARCH type models for the non-periodic intradaily volatility clustering tends to falter, in the sense that the estimated parameters obtained for different intradaily sampling frequencies are at odds with the temporal aggregation results developed by Drost and Nijman (1993), as well as the consistency theorems for continuous time diffusions and misspecified ARCH models derived by Nelson (1990, 1992); for existing evidence along these lines pertaining to the DM-\$ rates analyzed here see Andersen and Bollerslev (1996a), Ghose and Kroner (1996) and Guillaume, Pictet and Dacorogna (1995). Thus, it appears that multiple volatility components are necessarily required in order to fully explain the complex intradaily dependencies that are present in all the major financial markets. ${ }^{6}$

The attempt to associate each of the underlying volatility components with explicit economic factors seems destined to fail. Meanwhile, the regularly scheduled releases of macroeconomic figures have been shown to induce heightened overall volatility immediately following the "news" release for a number of different financial instruments; for studies on the impact of macroeconomic announcements on high-frequency foreign exchange rates see Andersen and Bollerslev (1996b), Eddelbüttel and McCurdy (1996), Ederington and Lee (1993, 1995a, 1995b), Goodhart et al. (1993), Harvey and Huang (1991), Hogan and Melvin (1994), Ito and Roley (1987), and Payne (1996). Not surprisingly, the actual effect tends to vary according to the type of announcement. From the analysis in Andersen and Bollerslev (1996b) the three regularly scheduled macroeconomic announcements with the largest instantaneous impact on DM-\$ volatility during the present sample period are the U.S. Employment Report, the biweekly Bundesbank meetings and the U.S. Durable Goods figures. ${ }^{7}$ To gauge the dynamic impact of each of these events, we consider the following simple AR(1) model for the standardized five-minute DM- $\$$ absolute returns, augmented by a separate short-lived AR(1) component,

\footnotetext{
6 A multiple components, or Heterogeneous, ARCH model have been proposed by Müller et al. (1995) to explicitly capture this phenomenon in the modelling of high-frequency foreign exchange returns. Components type model for daily stock return and interest rate volatility have also been estimated by Engle and Lee (1993) and Palm and Urbain (1995), and Jones, Lamont and Lumsdaine (1996), respectively.

7 The U.S. Employment Report, Durable Goods figures, and Business Inventories analyzed below, are all announced on a monthly schedule.
} 


$$
\left|\bar{R}_{t}\right|=\gamma+\gamma_{N} \cdot I_{N}(t)+\phi \cdot\left|\tilde{R}_{t-1}\right|+\phi_{N} \cdot D_{N}(t) \cdot\left|\tilde{R}_{t-1}\right|+\epsilon_{t}
$$

where the $I_{N}(t)$ indicator variable equals unity if an announcement of the given type, $N$, occurred during the t'th time interval and zero otherwise, while the "news" dummy, $D_{N}(t)$, equals unity for the two hours immediately following the event; i.e., $D_{N}(t) \equiv I_{N}(t)+I_{N}(t-1)+\ldots+I_{N}(t-23)$. In order to avoid confounding the dynamic dependencies by the strong intradaily volatility patterns, the returns in equation (1) are standardized by the average absolute return for the particular 5-minute interval; i.e., $\left|\tilde{R}_{1}\right| \equiv 260 \cdot\left|\mathbf{R}_{(\tau-1) \cdot 288+n}\right| \cdot\left(\sum_{\tau=1}^{260}\left|\mathbf{R}_{(\tau-1) \cdot 288+n}\right|\right)^{-1}$ for $\mathrm{n}=1,2, \ldots, 288$, and $\tau=1,2, \ldots, 260 .^{8}$ The first order sample autocorrelation for these standardized returns, i.e., $I_{N}(t)$ and $D_{N}(t) \equiv 0$ for all $t$, equals $\hat{\phi}=0.273$. However, the estimates obtained from the simple descriptive model in equation (1) suggest that the three major announcements result in their own distinct volatility response pattern. Specifically, for the Employment Report $\hat{\gamma}_{\mathrm{N}}=5.346(1.424)$ and $\phi_{\mathrm{N}}=-0.081$ (0.050), respectively, where the numbers in parentheses represent robust standard errors. These estimates therefore indicate an immediate increase in the volatility, but largely unaltered short-run dynamic dependencies in the two hours following the release of the report. Meanwhile, the estimates for the Bundesbank biweekly meetings are $1.394(0.651)$ and $0.102(0.054)$, suggestive of a slower rate of decay in the volatility component associated with this "news" release. The Durable Goods report also elevates volatility, $\hat{\gamma}_{N}=1.801(0.687)$, but the estimated short-run decay is actually faster than average with $\hat{\phi}_{\mathrm{N}}=-0.130(0.037)$, or $\hat{\phi}+\hat{\phi}_{\mathrm{N}}=0.144$. Many other announcements share this dynamic pattern. For instance, for the Business Inventory figures the same two parameters are $0.021(0.110)$ and $-0.094(0.045)$, respectively.

This relatively rapid decay of the readily identifiable "news" effects at the intradaily frequencies is in sharp contrast to the well documented highly persistent volatility clustering that is present at the lower interdaily frequencies. A voluminous literature surveyed in Bollerslev, Chou and Kroner (1992) have argued that the volatility processes for most speculative returns are close to being integrated in the variance in the sense of the IGARCH model of Engle and Bollerslev (1986); for evidence pertaining to daily foreign exchange rates see, e.g., Baillie and Bollerslev (1989), Bollerslev and Engle (1993) and Hsieh (1989). More recently however, Baillie, Bollerslev and

\footnotetext{
8 Much more elaborate standardization procedures for characterizing the average intradaily volatility pattems have recently been developed by Andersen and Bollerslev (1996a, 1996b) and Dacorogna et al. (1993).
} 
Mikkelsen (1996), Dacorogna et al. (1993), and Harvey (1994), have questioned these earlier findings, on the grounds that the long-run dependence in the volatility of interdaily foreign exchange returns is better characterized by a slowly mean-reverting fractionally integrated process. ${ }^{9}$ While shocks to the daily volatility process are highly persistent, it appears that they eventually dissipate, albeit at a very slow hyperbolic rate. As discussed in section 4, the approximate linear behavior of the estimated spectrum for $\left|R_{t}\right|$, when plotted on the double logarithmic scale in figure 1 , is consistent with this long-memory type dependence. Similarly, the rapid initial decay followed by the decidedly slower rate of dissipation for the longer-run autocorrelations in figure 2 are also suggestive about the existence of long-memory type dependencies, although the marked intradaily periodicity severely complicates the interpretation of the overall pattern in the autocorrelogram for the raw absolute returns.

\section{THE THEORETICAL VOLATILITY MODEL}

This section demonstrates that the mixture-of-distributions hypothesis, originally advocated by Clark (1973), Epps and Epps (1976), and Tauchen and Pitts (1983), provides a framework for rationalizing the complicated, and seemingly conflicting, behavior of the return volatility dynamics that exist at the inter- and intradaily frequencies; see also the analyses in Andersen (1996), Harris (1987), Ross (1989), and Taylor (1994). Intuitively, the mixture-of-distributions hypothesis stipulates that the return generating process reflects the impact of a large number of innovations to the information processes associated with the economic factors of relevance for the valuation of the asset in question. While the innovations, by definition, are serially uncorrelated, they are not likely to be independent since information of a particular kind tends to be positively autocorrelated, thus inducing the kind of dependence in the absolute, or second order, moments of the returns discussed above.

To formalize these ideas, consider the following representation for the intradaily returns,

$$
\mathrm{R}_{\mathrm{t}}=\mathrm{r}_{\mathrm{t}}-\mathrm{m}_{\mathrm{t}}=\mathrm{V}_{\mathrm{t}}^{1 / 2} \cdot \mathrm{Z}_{\mathrm{t}}
$$

\footnotetext{
9 Similar long-run dependencies in daily stock market volatility have been observed by Bollerslev and Mikkelsen (1996a, 1996b), Breidt, Crato and de Lima (1995), Ding and Granger (1996), Ding, Granger and Engle (1993), Gallant, Hsieh and Tauchen (1994), Granger and Ding (1996a, 1996b), Liu (1995), and McCurdy and Michaud (1996).
} 
where $m_{t}$ denotes the conditional mean of the raw returns, $r_{l}, Z_{t}$ is an i.i.d. stochastic process with mean zero and variance one, and the non-negative, positively serially-correlated mixing variable, $V_{t}$, serves as a proxy for the aggregate amount of information flow to the market. Equation (2) assumes the typical form associated with the discrete time ARCH class of models in which both $m_{t}$ and $V_{t}$ are assumed measurable with respect to the time t-1 observable information set, so that the conditional variance of the return equals $\operatorname{Var}_{t-1}\left(R_{t}\right)=\operatorname{Var}_{t-1}\left(r_{t}\right)=V_{t}$. More generally, however, the information flow is not directly observable, and $\mathrm{V}_{\mathrm{t}}$ is naturally modeled as a latent, or stochastic, volatility process; see, e.g., Andersen (1992) for further discussion. Of course, lacking additional assumptions regarding the temporal dependencies in the $\mathrm{V}_{\mathrm{t}}$ process, the model in equation (2) is void of testable empirical implications in regards to the observed volatility dynamics.

The rest of this section develops a specific representation of equation (2) that affords an interpretation of volatility as governed by heterogeneous information arrivals, while retaining the capacity of reconciling the seemingly conflicting evidence regarding volatility at the various return frequencies, and producing interesting empirical implications that are directly testable.

\subsection{Volatility as a Manifestation of Heterogeneous Information Arrivals}

Motivated by the empirical observations in section 2, we assume that the volatility process reflects the aggregate impact of $\mathrm{N}$ distinct information arrival processes; say $V_{j, t} \geq 0$, where $j=1,2, \ldots, N$. Also, following Andersen (1994), the temporal dependence of each constituent component is expressed in terms of a standard log-normal stochastic volatility, or Exponential SARV, model,

$$
\nu_{\mathrm{j}, \mathrm{l}}=\alpha_{\mathrm{j}} \cdot \nu_{\mathrm{j}, \mathrm{l}-1}+\epsilon_{\mathrm{j}, \mathrm{l}},
$$

where $\nu_{\mathrm{j}, \mathrm{t}} \equiv \ln \left(\mathrm{V}_{\mathrm{j}, \mathrm{t}}\right)-\mu_{\mathrm{j}}, \mu_{\mathrm{j}} \equiv \mathrm{E}\left[\ln \left(\mathrm{V}_{\mathrm{j}, \mathrm{t}}\right)\right]$, and the $\epsilon_{\mathrm{j}, \mathrm{t}}$ 's are assumed to be i.i.d. $\mathrm{N}\left(0, \sigma_{\mathrm{j}}^{2}\right)$ for all $\mathrm{j}$, $j=1,2, \ldots, N$. The logarithmic formulation in equation ( 3 ) ensures that the number of information arrivals dictated by the $\mathrm{j}$ 'th component process, $\mathrm{V}_{\mathrm{j}, \mathrm{t}} \equiv \exp \left(\nu_{\mathrm{j}, \mathrm{t}}+\mu_{\mathrm{j}}\right)$, is positive. The autoregressive coefficient, $\alpha_{\mathrm{j}}$, reflects the degree of persistence in the $\mathrm{j}$ 'th information arrival process. Consistent with the notion of positively serially-correlated but stationary "news" arrivals, we restrict these parameters to fall within the unit interval; i.e., $0 \leq \alpha_{\mathrm{j}}<1$.

According to the mixture-of-distributions hypothesis, each information arrival process has an 
effect on the aggregate latent volatility process. Assume that this combined effect may be represented by the geometric average of the constituent volatility components,

$$
\mathrm{V}_{\mathrm{t}}=\exp \left(\nu_{\mathrm{t}}+\mu_{\mathrm{v}}\right)
$$

where $\nu_{\mathrm{t}} \equiv \Sigma_{\mathrm{j}=1}^{\mathrm{N}} \nu_{\mathrm{j}, \mathrm{l}}$ and $\mu_{\nu} \equiv \Sigma_{\mathrm{j}=1}^{\mathrm{N}} \mu_{\mathrm{j}}$. Note, the spectrum for the aggregate $\nu_{\mathrm{t}}$ process at frequency $\omega$ is simply given by the sum of the spectra for the $N$ underlying independent AR(1) processes, i.e.,

$$
\mathrm{f}_{\nu}(\omega)=\mathrm{N}^{-1} \cdot(2 \pi)^{-1} \cdot \Sigma_{\mathrm{j}=1}^{\mathrm{N}} \sigma_{\mathrm{j}}^{2} \cdot\left|1-\alpha_{\mathrm{j}} \cdot \exp (-\mathrm{i} \cdot \omega)\right|^{-2},
$$

where $0 \leq \omega \leq \pi$. For small values of $N$, this spectral representation for $\nu_{1}$ can in principle be used to maximize Whittle's frequency domain approximation to the likelihood function for $\ln \left(\mathrm{R}_{\mathrm{t}}^{2}\right)=$ $\mu_{\nu}+\nu_{t}+\ln \left(Z_{t}^{2}\right)$ as specified by equations (2), (3) and (4); see Breidt, Crato and de Lima (1995) for an application of this frequency-domain based likelihood procedure in the estimation of a stochastic volatility model. Alternatively, the model may be estimated by any one of the Markov Chain Monte Carlo methods described in Jacquier, Polson and Rossi (1994) and Shephard (1996), or by the Efficient Method of Moments developed by Gallant and Tauchen (1996) as applied by Andersen and Lund (1996) and Gallant, Hsieh and Tauchen (1994). Yet, in the actual empirical implementation with high frequency data, a large number of heterogeneous information arrival processes is likely called for, rendering any of these direct estimation procedures for determining the $\alpha_{\mathrm{j}}$ 's as well as the remaining model parameters intractable.

In light of this, suppose that the heterogeneity in the individual component processes, as dictated by the $\operatorname{AR}(1)$ parameters, may be approximated by the normalized beta distribution,

$$
\mathrm{dF}_{\alpha}(\alpha)=2 \cdot \mathrm{B}(\mathrm{p}, \mathrm{q})^{-1} \cdot \alpha^{2 \mathrm{p}-1} \cdot\left(1-\alpha^{2}\right)^{\mathrm{q}-1} \mathrm{~d} \alpha
$$

where $0 \leq \alpha<1,0<\mathrm{p}, 1<\mathrm{q}<2$, and the beta function is given by $\mathrm{B}(\mathrm{p}, \mathrm{q}) \equiv \int_{0}^{1} \mathrm{x}^{\mathrm{p}-\mathrm{l}}(1-\mathrm{x})^{\mathrm{q}-1} \mathrm{dx}$ $=\Gamma(p) \cdot \Gamma(q) \cdot \Gamma(p+q)^{-1}$. This parametric density function allows for a wide variety of shapes in the bounded distribution of the $\alpha_{\mathrm{j}}$ 's, and thus provides a flexible way of characterizing different forms for dynamic dependencies in the latent information arrival processes; see, e.g., Johnson and Kotz (1970) for a discussion of the beta distribution. Moreover, this particular distributional assumption 
regarding the heterogeneity in the underlying $\nu_{\mathrm{j}, \mathrm{L}}$ processes has a number of testable implications in regards to the dynamic dependencies in the observable process for the absolute returns.

Specifically, consider the situation in which the number of component processes is arbitrarily large; i.e., $\mathrm{N} \rightarrow \infty$, so that $\mathrm{N}^{-1}$ times the sum of the individual AR(1) spectra in equation (5) converges to the probability weighted integral over the distribution for the $\alpha_{\mathrm{j}}$ coefficients. ${ }^{10}$ Following Granger (1980), the resulting spectrum for the $\nu_{\mathrm{t}}$ process may then be evaluated as,

$$
\begin{aligned}
\mathrm{f}_{\nu}(\omega)= & (2 \pi)^{-1} \cdot \sigma_{\epsilon}^{2} \cdot \int_{0}^{1}|1-\alpha \cdot \exp (-\mathrm{i} \cdot \omega)|^{-2} \mathrm{dF}_{\alpha}(\alpha) \\
= & (2 \pi)^{-1} \cdot \sigma_{\epsilon}^{2} \cdot 2 \cdot \mathrm{B}(\mathrm{p}, \mathrm{q})^{-1} \cdot \Sigma_{\mathrm{j}=-\infty}^{\infty}\left[\int_{0}^{1} \alpha^{2 p+|j|-1} \cdot\left(1-\alpha^{2}\right)^{q-2} \mathrm{~d} \alpha\right] \cdot \exp (-\mathrm{i} \cdot \omega \cdot \mathrm{j}) \\
= & (2 \pi)^{-1} \cdot \sigma_{\epsilon}^{2} \cdot \Gamma(\mathrm{p}+\mathrm{q}) \cdot \Gamma(\mathrm{q}-1) \cdot \Gamma(\mathrm{p})^{-1} \cdot \Gamma(\mathrm{q})^{-1} \\
& \Sigma_{\mathrm{j}=-\infty}^{\infty}\left[\Gamma(\mathrm{p}+1 / 2|\mathrm{j}|) \cdot \Gamma(\mathrm{p}+\mathrm{q}-1+1 / 2|\mathrm{j}|)^{-1}\right] \cdot \exp (-\mathrm{i} \cdot \omega \cdot \mathrm{j}),
\end{aligned}
$$

where $\sigma_{\epsilon}^{2} \equiv \lim _{\mathrm{N} \rightarrow \infty} \mathrm{N}^{-1} \sum_{\mathrm{j}=1}^{\mathrm{N}} \sigma_{\mathrm{j}}^{2}$. Alternatively, the spectrum for the $\nu_{\mathrm{t}}$ process may be written as $\mathrm{f}_{\nu}(\omega)$ $\equiv \sigma_{v}^{2} \cdot(2 \pi)^{-1} \cdot \Sigma_{\mathrm{j}=-\infty}^{\infty} \rho\left(\nu_{\mathrm{t}}, \mathrm{j}\right) \cdot \exp (-\mathrm{i} \cdot \omega \cdot \mathrm{j})$, where $\sigma_{v}^{2}$ and $\rho\left(\nu_{\mathrm{t}}, \mathrm{j}\right)$ denote the variance and the $\mathrm{j}$ 'th order autocorrelation for $\nu_{\mathrm{t}}$, respectively. Thus, by equating terms in the identical powers of $\mathrm{j}$, it follows that the autocorrelations for $\nu_{\mathrm{t}}$ must be proportional to $\Gamma(\mathrm{p}+1 / 2|\mathrm{j}|) \cdot \Gamma(\mathrm{p}+\mathrm{q}-1+1 / 2|\mathrm{j}|)^{-1}$. This implies that for large $|j|$, the autocorrelations for the aggregate latent logarithmic volatility process behaves like, ${ }^{11,12}$

$$
\rho\left(\nu_{\mathrm{r}}, \mathrm{j}\right) \sim \mathrm{j}^{\mathrm{l}-\mathrm{q}}
$$

The dependence in $\nu_{\mathrm{r}}$ will therefore dissipate at the slow hyperbolic rate of decay associated with the

\footnotetext{
10 This is, of course, a standard technique for evaluation of the effects of aggregation, see Theil (1954).

11 By Stirling's Formula $\Gamma(a+j) \cdot \Gamma(b+j)^{-1} \approx c-j^{-a-b}$ for large $j$, where $c$ is a factor of proportionality.

12 This same idea has recently been employed by Ding and Granger (1996) in imposing a slowly hyperbolically decaying structure on the parameters in a GARCH type model for daily stock returns.
} 
covariance stationary fractionally integrated, or $I(d)$, class of models, with $d=1-1 / 2 \cdot q \cdot{ }^{13}$

Of course, the mixture-of-distributions hypothesis in equation (2) is phrased in terms of the latent volatility process, $V_{t}$, and not $\nu_{t}$. However, it is readily demonstrated that the long-run dependence induced in the autocorrelations for $\nu_{\mathrm{t}}$, for $0<\mathrm{d}=1-1 / 2 \cdot \mathrm{q}<1 / 2$, carries over to any positive power transform of the fundamental $\mathrm{V}_{\mathrm{t}}$ process; say $\mathrm{V}_{\mathrm{t}}^{\theta}=\exp ^{\theta}\left(\nu_{\mathrm{t}}+\mu_{\nu}\right)$, where $\theta>0$. First, note that $\mathrm{E}\left(\mathrm{V}_{\mathrm{l}}^{\theta} \cdot \mathrm{V}_{\mathrm{t}-\mathrm{j}}^{\theta}\right)=\left[\mathrm{E}\left(\mathrm{V}_{\mathrm{l}}^{\theta}\right)\right]^{2} \cdot \exp \left[\theta^{2} \cdot \rho\left(\nu_{\mathrm{t}}, \mathrm{j}\right) \cdot \sigma_{\nu}^{2}\right]$; see Granger and Newbold (1976) for a general discussion regarding the autocorrelation functions of power transforms of normals, and Andersen (1994) for a more detailed analysis of the particular case analyzed here. Consequently, the $j$ 'th order autocorrelation for $V_{1}^{\theta}$ may be written as,

$$
\rho\left(\mathrm{V}_{\mathrm{l}}^{\theta}, \mathrm{j}\right)=\left[\exp \left(\theta^{2} \cdot \sigma_{\nu}^{2}\right)-1\right]^{-1} \cdot\left[\exp \left\{\theta^{2} \cdot \sigma_{\nu}^{2} \cdot \rho\left(\nu_{\mathrm{l}}, \mathrm{j}\right)\right\}-1\right]
$$

However, $\rho\left(\nu_{\mathrm{t}}, \mathrm{j}\right) \sim \mathrm{j}^{2 \mathrm{~d}-1} \rightarrow 0$ for $\mathrm{j} \rightarrow \infty$, so that by a first order Taylor series expansion $\exp \left[\theta^{2} \cdot \sigma_{\nu}^{2} \cdot \rho\left(\nu_{\mathrm{t}}, \mathrm{j}\right)\right] \approx 1+\theta^{2} \cdot \sigma_{v}^{2} \cdot \rho\left(\nu_{\mathrm{t}}, \mathrm{j}\right)$. From this it follows immediately that, for large $\mathrm{j}$,

$$
\rho\left(\mathrm{V}_{\mathrm{t}}^{\theta}, \mathrm{j}\right) \approx\left[\exp \left(\theta^{2} \cdot \sigma_{\nu}^{2}\right)-1\right]^{-1} \cdot \theta^{2} \cdot \sigma_{\nu}^{2} \cdot \rho\left(\nu_{\mathrm{t}}, \mathrm{j}\right) \sim \mathrm{j}^{2 \mathrm{~d}-1} .
$$

Thus, the $\mathrm{V}_{\mathrm{l}}^{\theta}$ and the $\nu_{\mathrm{t}}$ processes share the same long-run decay in their autocorrelation functions.

More importantly, this long-run dependence in the $\mathrm{V}_{\mathrm{t}}^{\theta}$ process is propagated to the process for the absolute returns raised to an arbitrary power, $2 \cdot \theta$. To see this, note that from equation (2) any power transform of the absolute returns is directly related to the latent volatility process by $\left|R_{t}\right|^{2 \cdot \theta}=V_{t}^{\theta} \cdot\left|Z_{t}\right|^{2 \cdot \theta}$. Thus, because $Z_{t}^{2}$ is an i.i.d. process, it follows that $\rho\left(\left|R_{\mathrm{l}}\right|^{2 \cdot \theta}, j\right)$ is proportional to $\rho\left(\mathrm{V}_{\mathrm{t}}^{\theta}, \mathrm{j}\right)$. The return volatility will therefore exhibit the identical slow hyperbolic rate of decay whether measured in terms of the absolute returns, $\left|R_{t}\right|$, the squared returns, $R_{t}^{2}$, or any other power transform, $\left|R_{\imath}\right|^{2 \cdot \theta}$; i.e., for large $j$,

$$
\rho\left(\left|R_{t}\right|^{2 \cdot \theta}, j\right)-j^{2 d-1} .
$$

13 The process $y_{1}$ is integrated of order $d$, or $I(d)$, if $(1-L)^{d} y_{t}$ is stationary and ergodic with a positive and bounded spectrum across all frequencies, where the fractional differencing operator $(1-\mathrm{L})^{\mathrm{d}}$ is defined by the binomial expansion, (1-L) ${ }^{\mathrm{d}}$ $\equiv \Sigma_{\mathrm{j}=0} \quad \Gamma(\mathrm{j}-\mathrm{d}) \cdot \Gamma(\mathrm{j}+\mathrm{l})^{-1} \cdot \Gamma(-\mathrm{d}) \cdot \mathrm{L}^{\mathrm{j}}$. If $0<\mathrm{d}<1 / 2$ the autocorrelations for $\mathrm{y}_{\mathrm{l}}$ are all eventually positive, and decay at a hyperbolic rate. For recent surveys of the relevant literature see e.g. Baillie (1996), Beran (1994) and Robinson (1994b). 
This result is important because it demonstrates how the long-memory features of volatility may arise naturally through the interaction of a large number of diverse information processes. From a conceptual perspective, it implies that the long-memory characteristics reflect inherent properties of the return generating process, rather than external shocks that induce a structural shift in the volatility process, as, e.g., suggested by Lamoureux and Lastrapes (1990). In other words, the mechanism responsible for the fractional integration in volatility is generic to the returns process, and thus ever present, so that with high frequency data it may be feasible to identify the manifestation of the phenomenon even over relatively short spans of calendar time. We pursue this possibility in section 4.

For now, we simply note that the result in equation (11) is consistent with the empirical behavior of the autocorrelograms for the various power transforms of daily equity returns reported in Ding, Granger and Engle (1993). Although Harvey and Streibel (1996) argue that it is impossible, by theoretical means, to ascertain which value of $\theta$ will uniformly maximize the autocorrelations for the simple stochastic volatility model, corresponding to $\mathrm{N}=1$ in the current setup, it is noteworthy that the sample autocorrelations for the daily returns analyzed in Ding, Granger and Engle (1993) attain their maxima for $\theta$ very close to one-half. ${ }^{14}$ Motivated by this observation, we concentrate on the correlation structure for the intradaily absolute returns in the empirical investigations reported on below. ${ }^{15}$

\subsection{Temporal Aggregation of Volatility}

The long memory characterization obtained in equation (11) may appear incomplete, because the mixture-of-distributions hypothesis is silent regarding the proper discrete time sampling interval for the intradaily return series. While the complex volatility structure entertained renders a full distributional characterization of the volatility process for arbitrary sampling frequencies infeasible, it is possible to show that the autocorrelations for temporally aggregated squared returns eventually exhibit the identical long-run hyperbolic rate of decay across all sampling intervals. In particular, let $\mathrm{R}_{\tau}^{(\mathrm{k})} \equiv \mathrm{R}_{\tau \cdot \mathrm{k}}+\mathrm{R}_{\tau \cdot \mathrm{k} \cdot 1}+\ldots+\mathrm{R}_{\tau \cdot \mathrm{k}-\mathrm{k}+1}=\mathrm{V}_{\tau \cdot \mathrm{k}}^{1 / 2} \cdot \mathrm{Z}_{\tau \cdot \mathrm{k}}+\mathrm{V}_{\tau \cdot \mathrm{k}-1}^{1 / 2} \cdot \mathrm{Z}_{\tau \cdot \mathrm{k}-1}+\ldots+\mathrm{V}_{\tau \cdot \mathrm{k}-\mathrm{k}+\mathrm{l}}^{\mathrm{l} / 2} \cdot \mathrm{Z}_{\tau \cdot \mathrm{k}-\mathrm{k}+1}$, where

14 This phenomenon is referred to as the Taylor effect by Granger and Ding (1996b).

15 For the 5-minute DM- $\$$ returns the first order sample autocorrelations for $\left|R_{1}\right|$ and $R_{t}^{2}$ equal 0.309 and 0.201 , respectively. 
$\tau=1,2, \ldots$, and $k=1,2, \ldots$, denote the temporally aggregated returns. ${ }^{16}$ Since the $Z_{t}$ 's are i.i.d., it follows that the $\mathrm{j}^{\prime}$ th order autocorrelation for $\left(\mathrm{R}_{\tau}^{(k)}\right)^{2}$ is proportional to the correlation between $V_{\tau \cdot k} \cdot Z_{\tau \cdot k}^{2}+V_{r \cdot k-1} \cdot Z_{\tau \cdot k-1}^{2}+\ldots+V_{r \cdot k-k+1} \cdot Z_{\tau \cdot k-k+1}^{2}$ and $V_{(\tau-j) \cdot k} \cdot Z_{(\tau-j) \cdot k}^{2}+V_{(\tau-j) \cdot k-1} \cdot Z_{(\tau-j) \cdot k-1}^{2}+$ $\ldots+\mathrm{V}_{(\tau-\mathrm{j}) \cdot \mathrm{k}-\mathrm{k}+1} \cdot \mathrm{Z}_{(r-\mathrm{j}) \cdot \mathrm{k}-\mathrm{k}+\mathrm{l}}^{2}$. Thus, by collecting terms corresponding to the same lag length, the latter correlation is, in turn, proportional to the sum of the autocorrelations between $V_{1}^{2}$ and $V_{t \cdot j \cdot k-h}^{2}$, where the weights corresponding to $h=-k+1,-k+2, \ldots, k-1$ are given by $(k-|h|)$, and zero otherwise. Consequently, for long lags, $\mathrm{j}$,

$$
\begin{aligned}
\rho\left(\left[\mathrm{R}_{\tau}^{(\mathrm{k})}\right]^{2},\left[\mathrm{R}_{\tau-\mathrm{j}}^{(\mathrm{k})}\right]^{2}\right) & \sim \mathrm{k}^{-2} \cdot \sum_{\mathrm{h}=-\mathrm{k}+1}^{\mathrm{k}-1}(\mathrm{k}-|\mathrm{h}|) \cdot \rho\left(\mathrm{V}_{\mathrm{t}}^{2}, \mathrm{~V}_{\mathrm{t}-\mathrm{j} \cdot \mathrm{k}-\mathrm{h}}^{2}\right) \\
& \sim \mathrm{k}^{-2} \cdot \Sigma_{\mathrm{h}=-\mathrm{k}+1}^{\mathrm{k}-1}(\mathrm{k}-|\mathrm{h}|) \cdot(\mathrm{j} \cdot \mathrm{k}+\mathrm{h})^{2 \mathrm{~d}-1} \\
& =(\mathrm{j} \cdot \mathrm{k})^{2 \mathrm{~d}-1} \\
& \sim \mathrm{j}^{2 \mathrm{~d}-1} .
\end{aligned}
$$

That is, the long-memory features of the squared returns are consistent with the characteristics of a self-similar process in the sense of Mandelbrot and van Ness (1968) and Mandelbrot and Wallis (1969). Moreover, by analogy to the $\mathrm{k}=1$ case detailed above, if the temporally aggregated latent volatility process is log-normally distributed, then the long-run autocorrelation structure for $\left|R_{+}^{(k)}\right|^{2 \cdot \theta}$ will be identical for all $\theta$. Thus, in this case the autocorrelations for any power transform of the temporally aggregated absolute returns should again eventually decay at the identical hyperbolic rate of $\mathrm{j}^{2 \mathrm{~d}-1}$ irrespective of the sampling frequency, $\mathrm{k} .{ }^{17}$

\subsection{Extensions}

Before we describe the empirical findings pertaining to the propositions developed so far, we should

16 For the 74,880 5-minute returns analyzed here an aggregation factor of $k=2$ would correspond to the time series of 37,44010 -minute returns, whereas $k=3$ refers to the time series of 24,96015 -minute returns, etc.

17 Previous empirical work with much simpler dependency structures have found the log-normal distribution to work remarkably well at various return frequencies; see e.g. Andersen (1996), Shephard (1996) and Taylor (1994). 
emphasize that the theoretical model readily accommodates extensions in a number of directions which allow for added flexibility and realism in the portrayal of the volatility dynamics without affecting the salient long-run dependencies. Firstly, the mixture-of-distributions hypothesis in equations (2), (3) and (4) obviously neglects the repetitive intradaily pattern in the volatility that is evident in the spectrum and the autocorrelogram for the 5-minute absolute DM-\$ returns in figures 1 and 2. To incorporate this periodicity, let $s(t)$ denote the stage of the periodic cycle at time $t$. A slight modification of the model in equation (2), that explicitly allows for the pronounced intradaily pattern, takes the form,

$$
\mathrm{R}_{\mathrm{t}}=\mathrm{V}_{\mathrm{t}}^{1 / 2} \cdot \mathrm{S}_{\mathrm{t}, \mathrm{s}(\mathrm{t})} \cdot \mathrm{Z}_{\mathrm{t}}
$$

where the spectrum for the independent seasonal component $S_{t, s(t)}$ has no mass at frequencies lower than one day. ${ }^{18}$ Since $\ln \left(\mathrm{R}_{\mathrm{t}}^{2}\right)=\mu_{\nu}+\nu_{\mathrm{t}}+\ln \left(\mathrm{S}_{\mathrm{t}, \mathrm{s}(\mathrm{l})}^{2}\right)+\ln \left(\mathrm{Z}_{\mathrm{t}}^{2}\right)$, it follows that the long-run behavior, as dictated by the spectrum for $\nu_{\mathrm{t}}$ near frequency zero, is unaffected by this additional periodic component. Of course, the autocorrelation structure in the absolute returns may be severely influenced by the presence of the repetitive intradaily pattern. However, as demonstrated below, by explicitly filtering out the daily and higher frequency dynamics in the absolute returns process, it is possible to uncover the long-run hyperbolic rate of decay implied by the aggregation of the component processes.

Rather than being independent, the "news" arrivals might more realistically share a number of common factors related to the state of the overall economy, while still exhibiting their own separate influence on the valuation of the asset. To allow for such common effects, consider the following generalization of the simple logarithmic AR(1) processes in equation (3),

$$
\nu_{\mathrm{j}, \mathrm{t}}=\alpha_{\mathrm{j}} \cdot \nu_{\mathrm{j}, \mathrm{t}-\mathrm{l}}+\Sigma_{\mathrm{k}=\mathrm{l}}^{\mathrm{K}} \xi_{\mathrm{j}, \mathrm{k}} \cdot \kappa_{\mathrm{k}, \mathrm{t}}+\epsilon_{\mathrm{j}, \mathrm{t}}
$$

where $\kappa_{\mathrm{k}, \mathrm{t}}$ represents the de-meaned $\mathrm{k}^{\prime}$ th common factor, and the factor loading for the $\mathrm{j}$ 'th arrival

\footnotetext{
18 A particularly simple representation that restricts $S_{t, s(1)}$ to depend only on the stage of the periodic cycle, $s(t)$, has been successfully employed by Andersen and Bollerslev (1996a) in modelling the periodicity in the DM- $\$$ retum series analyzed here. Note also that periodicities at, say, the weekly frequency may be accommodated analogously.
} 
process associated with common factor $\mathrm{k}$ is denoted by $\xi_{\mathrm{j}, \mathrm{k} \cdot}{ }^{19}$ Provided that each of the common factors are covariance stationary, so that their spectra are bounded across all frequencies, and that the heterogeneity in the individual persistence parameters, $\alpha_{j}$, is determined by the beta distribution in equation (6), it follows immediately by analogy to the results in Granger (1980), that the hyperbolic decay in the autocorrelation function for $\nu_{t}$ is preserved under this more general specification. The independence assumption in equation (3) merely serves to simplify the exposition. The implied degree of long-run dependence in the absolute returns remains intact under the more realistic assumptions in equation (14).

Finally, while the derivation above explicitly relies on the beta distribution in equation (6) for characterizing the heterogeneity in the individual component processes, it is obvious that the degree of fractional integration, $d=1-1 / 2 \cdot q$, is independent of the $p$ parameter in the beta distribution. Only the shape of the distribution for $\alpha$ close to unity, as dictated by $\mathrm{q}$, is important. Intuitively, if a sufficient number of the individual information arrival processes have high persistence, albeit $\alpha_{\mathrm{j}}<1$, the aggregate information arrival process will display long-memory characteristics. This suggests that the aggregation argument behind the long-run dependence in $\nu_{\mathrm{t}}$ is somewhat more general than portrayed above. Indeed, Lin (1991) and Granger and Ding (1996a) show that the so-called Generalized Integrated class of models, discussed by Granger $(1987,1988)$, may arise through the aggregation of a closely related component type structure. ${ }^{20}$

\section{ESTIMATING LONG-MEMORY IN VOLATILITY}

The theoretical framework developed in the previous section builds on the idea that the aggregate market volatility represents the manifestation of numerous heterogeneous information arrival processes; some with short-run volatility dependencies, others possessing more highly persistent volatility patterns. As time passes the short-run processes decay significantly, while the more highly persistent processes remain influential. Hence, while sudden bursts of volatility typically will possess both short-run and long-run components, the short-run decay stands out most clearly over the

\footnotetext{
19 Notice that this construction closely mirrors the spirit, if not the structure, of the arbitrage pricing theory of Ross (1976).

20 A related method for use in the simulation of fractional Gaussian noise has been proposed by Mandelbrot and Wallis (1969) and Mandelbrot (1971).
} 
intradaily frequencies, whereas the highly persistent processes only will be noticeable over longer horizons. However, traditional correlation based measures for the degree of volatility persistence, obtained from high frequency intradaily data, will tend to pick up only the effects of the complex interaction between the short-run decay associated with the less persistent processes and the strong intradaily periodicity, thus missing the importance of the long-run volatility components.

To illustrate, consider the third row in table 1 which reports the first order sample autocorrelation, $\hat{\rho}^{(\mathrm{k})}$, for the temporally aggregated absolute 5 -minute returns; i.e., $\left|\mathrm{R}_{\tau}^{(\mathrm{k})}\right|$ for $\tau=$ $1,2, \ldots, 74,880 / \mathrm{k}$. The first order sample autocorrelations for the highest intradaily frequencies all indicate very significant positive serial correlation in the absolute returns. However, there is sharp drop off in the value of the sample autocorrelations at the three hour sampling frequency, i.e., $\mathrm{k}=$ 36. In fact, the first order autocorrelations for the eight and twelve hours absolute returns, i.e., $k$ $=96$ and 144 , are both negative, suggestive of an anti-persistent volatility process. ${ }^{21,22}$

The latter conclusion is, of course, grossly misleading, being driven by the combined effects of the intradaily periodic pattern and the complex multiple volatility component structure, thus creating an overall system that conforms to the law of motion outlined in equation (13). In order to justify this interpretation, however, we must develop an alternative estimation approach. In particular, while strong intraday periodicity and pronounced volatility clustering have been extensively documented at the high frequency level, there is little direct evidence for the existence of longer-run volatility components that induce the type of long-memory behavior in the high frequency volatility process implied by our information aggregation rendition of the mixture-ofdistributions hypothesis.

Specifically, from the model detailed in the previous section, the absolute returns should exhibit the identical long-run dependence irrespective of the sampling frequency, say I(d), where 0 $<\mathrm{d}<1 / 2$. On representing the process for the absolute returns as $(1-\mathrm{L})^{\mathrm{d}}\left|\mathrm{R}_{\tau}^{(\mathrm{k})}\right|=\eta_{\tau}^{(\mathrm{k})}$, where $\eta_{\tau}^{(\mathrm{k})}$ is a stationary and ergodic process with a bounded spectrum, $f_{\eta, k}(\omega)$, for all frequencies, $\omega$, the

21 Müller et al. $(1993,1995)$ attribute this negative correlation for the half-day lag to a heterogeneous market with different groups of traders participating during their regular business hours.

22 This is also consistent with the $\operatorname{GARCH}(1,1)$ model estimates for the degree of volatility persistence in intradaily exchange rates reported in Andersen and Bollerslev (1996a), Ghose and Kroner (1996), and Guillaume, Pictet and Dacorogna (1995). The half-lives implied by the parameter estimates differ markedly across the intradaily sampling frequencies. 
spectrum for $\left|R_{\tau}^{(k)}\right|$ may therefore be written as, ${ }^{23}$

$$
\begin{aligned}
f_{|R|, k}(\omega) & =\left|[1-\exp (-i \cdot \omega)]^{-d}\right|^{2} \cdot f_{\eta, k}(\omega) \\
& =|2 \cdot \sin (1 / 2 \cdot \omega)|^{-2 \cdot d} \cdot f_{\eta, k}(\omega)
\end{aligned}
$$

Since, $\lim _{\omega \rightarrow \infty} \omega^{-1} \cdot \sin (1 / 2 \cdot \omega)=1 / 2$, it follows that for the frequencies close to zero, i.e., $\omega \approx 0$,

$$
\mathrm{f}_{|\mathrm{R}|, \mathrm{k}}(\omega) \approx \mathrm{f}_{\eta, \mathrm{k}}(0) \cdot|\omega|^{-2 \cdot d}
$$

or,

$$
\ln \left[f_{|R|, k}(\omega)\right] \approx \ln \left[f_{\eta, k}(0)\right]-2 \cdot d \cdot \ln (\omega)
$$

Hence, the spectrum should be approximately log-linear for the long-run frequencies. Indeed, when viewed on the double logarithmic scale in figure 1, the spectrum for the 5-minute absolute returns, i.e., $\mathrm{k}=1$, is very close to a straight line over the interdaily frequencies, $0<\omega<2 \cdot \pi / 288 \approx$ 0.0218 .

The Geweke and Porter-Hudak (1983) log-periodogram regression estimate for the fractional order of integration is based directly on this relationship. These estimates for the dependence in $\left|\mathbf{R}_{\tau}^{(\mathrm{k})}\right|$, obtained across all of the intradaily frequencies, are reported in the column labelled $\hat{\mathrm{d}}_{\mathrm{GH}}^{(\mathrm{k})}$ in table 1. Formally,

$$
\hat{\mathrm{d}}_{\mathrm{GH}}^{(\mathrm{k})}=-1 / 2 \cdot\left\{\Sigma_{\mathrm{j}=\ell+1}^{\mathrm{m}}\left[\ln \left(\omega_{\mathrm{k}, \mathrm{j}}\right)-\bar{\omega}_{\mathrm{k}, \ell, \mathrm{m}}\right] \cdot \ln \left(\mathrm{I}_{|\mathrm{R}|, \mathrm{k}}\left(\omega_{\mathrm{j}, \mathrm{k}}\right)\right)\right\} \cdot\left\{\Sigma_{\mathrm{j}=\ell+1}^{\mathrm{m}}\left[\ln \left(\omega_{\mathrm{k}, \mathrm{j}}\right)-\bar{\omega}_{\mathrm{k}, \ell, \mathrm{m}}\right]^{2}\right\}^{-1},
$$

where $\bar{\omega}_{\mathrm{k}, \ell, \mathrm{m}} \equiv(\mathrm{m}-\ell)^{-1} \cdot \Sigma_{\mathrm{j}=\ell+1}^{\mathrm{m}} \omega_{\mathrm{j}, \mathrm{k}}$, and $\mathrm{I}_{|\mathrm{R}|, \mathrm{k}}\left(\omega_{\mathrm{j}, \mathrm{k}}\right)$ denotes the sample periodogram for $\left|\mathrm{R}_{\tau}^{(\mathrm{k})}\right|$ at the j'th Fourier frequency, i.e., $\omega_{\mathrm{j}, \mathrm{k}}=2 \cdot \pi \cdot \mathrm{j} \cdot \mathrm{k} / \mathrm{T}$. Although this estimator for $\mathrm{d}$ has been fairly widely used in the literature, consistency for $0<d<1 / 2$ has only recently been established by Robinson (1995) under regularity conditions that include the truncation and trimming parameters both tending to infinity, albeit at a slower rate than the sample size; i.e., $\mathrm{m} \rightarrow \infty, \ell \rightarrow \infty, \ell / \mathrm{m} \rightarrow 0$, and $\mathrm{m} \cdot \mathrm{k} / \mathrm{T}$

23 Formal conditions for the equivalence between this spectral definition of long-memory and the hyperbolic decay rate in the autocorrelation function are discussed in Beran (1994) and Robinson (1994b); see also Granger and Ding (1996a). 
$\rightarrow 0$. However, the regularity conditions also require that $\left|R_{r}^{(k)}\right|$ be normally distributed, which in turn implies that the estimator itself, $\hat{\mathrm{d}}_{\mathrm{GH}}^{(\mathrm{k})}$, is asymptotically normal with a variance equal to $\mathrm{m}^{-}$ ${ }^{1} \cdot\left(\pi^{2} / 24\right)$, independent of the sample size, $\mathrm{T} / \mathrm{k}$.

For derivation of the results reported on in table 1 , we took $\mathrm{m}=\left[(\mathrm{T} / \mathrm{k})^{1 / 2}\right]$ and $\ell=\left[\mathrm{m}^{1 / 4}\right]$, respectively, where [·] denotes the integer value. However, in order to avoid any confounding effects from frequencies corresponding to less than one day, the estimate for $\hat{d}_{G H}^{(1)}$ is based on $m=$ 255 and $\ell=3$. Note that, in contrast to the sample autocorrelations reported in the $\hat{\rho}^{(\mathrm{k})}$ column, the $\hat{\mathrm{d}}_{\mathrm{GH}}^{(\mathrm{k})}$ estimates for the degree of long-run volatility dependence are remarkably stable across the different intradaily return intervals. In fact, when judged by the asymptotic normal distributions, all of the estimates are within less than one asymptotic standard error of $d=0.359 .{ }^{24}$ To illustrate, consider the estimate for $\hat{d}_{G H}^{(1)}=0.321$, corresponding to the average slope of the spectrum for the 5 -minute absolute returns in figure 1 over the frequencies $0<\omega \leq 255 \cdot 2 \cdot \pi / 74,888 \approx 0.0214 .{ }^{25}$ The theoretical standard error for this estimate equals $\pi \cdot(24 \cdot 255)^{-1 / 2} \approx 0.040$. As such, the estimates for $\mathrm{k}=1,2, \ldots, 144$ confirm the proposition that the degree of fractional integration in the absolute returns is invariant with respect to the sampling frequency. ${ }^{26}$

Unfortunately, the assumption of normality underlying the formal statistical justification for the $\hat{\mathrm{d}}_{\mathrm{GH}}^{(\mathrm{k})}$ estimates is clearly violated in the present context. For instance, the sample skewness and kurtosis for the absolute 5 -minute returns equal 0.367 and 21.5 , respectively. The last column in table 1 therefore reports the results from a less restrictive semiparametric estimation procedure for determining $d$, based on the ratio of the periodogram for two frequencies close to zero. ${ }^{27}$ To motivate this estimator, let

$$
\mathrm{G}_{\mathrm{m}, \mathrm{k}}=2 \cdot \pi \cdot(\mathrm{T} / \mathrm{k})^{-1} \cdot \Sigma_{\mathrm{j}=1}^{\mathrm{m}} \mathrm{I}_{|\mathrm{R}|, \mathbf{k}}\left(\omega_{\mathrm{j}, \mathrm{k}}\right)
$$

24 This value of $d$ corresponds to the estimated hyperbolic decay rate in the low-pass filtered 5-minute absolute returns described further in section 5 below.

25 Including all of the frequencies up to $\mathrm{j}=\left[74,880^{1 / 2}\right]=273$, the estimate for $\dot{d}_{G H}^{(1)}$ drops to a value of only 0.242 , highlighting the importance of explicitly excluding the intradaily effects in the estimation.

26 This is also consistent with the notion of an intrinsic time scale in the foreign exchange market as discussed by Müller et al. (1993).

27 The same log-periodogram and average periodogram estimators for $d$ implemented here have previously been employed by Delgado and Robinson (1994) in the analysis of a time series of monthly Spanish inflation rates. 
denote the average periodogram for the frequencies $\mathrm{j}=1,2, \ldots, \mathrm{m}$. Then, following Robinson (1994a), for $0<d<1 / 2$ and $m \rightarrow \infty$, but $m \cdot k / T \rightarrow 0$,

$$
\ln \left(G_{m, k}\right)-\ln \left(G_{[q m], k}\right)+(1-2 \cdot d) \cdot \ln (q) \approx 0,
$$

where $0<\mathrm{q}<1$. Thus, upon rearranging the terms in equation (20), the following estimator for d becomes apparent,

$$
\hat{\mathrm{d}}_{\mathrm{AP}}^{(\mathrm{k})}=1 / 2+1 / 2 \cdot \ln (\mathrm{q})^{-1} \cdot\left[\ln \left(\mathrm{G}_{\mathrm{m}, \mathrm{k}}\right)-\ln \left(\mathrm{G}_{[\mathrm{qm}], \mathrm{k}}\right)\right]
$$

Consistency of this frequency-domain estimator for $d$ has been established by Robinson (1994a) under much weaker regularity conditions than those available for $\hat{\mathrm{d}}_{\mathrm{GH}}^{(\mathrm{k})}$. Furthermore, given the assumption of normality underlying the existing consistency proof for the log-periodogram estimator, $\hat{\mathrm{d}}_{\mathrm{GH}}^{(\mathrm{k})}$, Lobato and Robinson (1996) have recently shown that the alternative $\hat{\mathrm{d}}_{\mathrm{AP}}^{(k)}$ estimator is asymptotically normal for $0<\mathrm{d}<1 / 4$, but non-normally distributed for $1 / 4 \leq \mathrm{d}<1 / 2$.

The estimates reported in the last column of table 1 are based on a truncation parameter of $\mathrm{m}=\left[(\mathrm{T} / \mathrm{k})^{1 / 2}\right]$ for $\mathrm{k}=2,3, \ldots, 144$, whereas $\mathrm{m}=255$ for $\mathrm{k}=1$ in order to avoid any confounding effects from the intradaily dependencies in the estimation of $\hat{d}_{A P}^{(1)}$. The value for the scalar $q$ was fixed at 0.25 across all the sampling frequencies. In line with the simulation evidence reported in Lobato and Robinson (1996), some informal sensitivity analysis revealed the results to be fairly robust with respect to this choice. Turning to the actual estimates, the similarities across the different values of $\mathrm{k}$ are even more striking than for the log-periodogram estimates. The average value of $\hat{d}_{A P}^{(k)}$ equals 0.321 , while ranging from a low of 0.270 for $k=72$ to a high of only 0.385 for $\mathrm{k}=1 .^{28}$

Consistent with the notion of a heterogeneous component structure and the invariance under temporal aggregation, these estimates for $d$, based on a single year of intradaily returns, are also very much in line with previously reported estimates for much longer time spans of daily data. For instance, on calculating the same log-periodogram regression and average periodogram estimates for the fractional order of integration for the time series of 3,649 daily DM-\$ absolute returns from

\footnotetext{
28 The estimate for $\hat{d}_{A P}^{(1)}$ corrupted by the intradaily frequencies, or $\mathrm{j}=256,257, \ldots, 273$, equals 0.172 .
} 
March 14, 1979 through September 29, 1993, the estimates are 0.344 and 0.301 , respectively. ${ }^{29}$ Thus, the relatively simple semiparametric frequency-domain estimators in equations (18) and (21) are both capable of uncovering the inherent long-run volatility dependencies in the time series of high-frequency intradaily returns, without having to impose any specific structure on the short-run behavior of the system in order to accommodate the complex intradaily dynamics and repetitive periodic patterns that corrupt the conventional correlation based measures.

To further appreciate the notion of long-memory volatility dynamics, consider the properties of the (1-L) ${ }^{d}$ filter designed to annihilate the long-run dependence in the absolute returns. Expressing the fractional differencing operator in terms of its binomial expansion, the gain of the corresponding filter may be written as,

$$
\left|[1-\exp (-\mathrm{i} \cdot \omega)]^{\mathrm{d}}\right|=\left\{\left[\Sigma_{\mathrm{j}=0, \ldots \infty} \delta_{\mathrm{j}} \cdot \cos (\omega \cdot \mathrm{j})\right]^{2}+\left[\Sigma_{\mathrm{j}=0, \ldots \infty} \delta_{\mathrm{j}} \cdot \sin (\omega \cdot \mathrm{j})\right]^{2}\right\}^{1 / 2}
$$

where $0 \leq \omega \leq \pi$, and $\delta_{\mathrm{j}} \equiv \Gamma(\mathrm{j}-\mathrm{d}) \cdot \Gamma(\mathrm{j}+1)^{-1} \cdot \Gamma(-\mathrm{d})$ for $\mathrm{j}=0,1, \ldots$. Intuitively, the gain at frequency $\omega$ represents the magnitude by which the filter multiplies the component of the time series with a repetitive cycle of $2 \cdot \pi / \omega$ periods. The enhanced flexibility provided by allowing for fractional orders of integration is evident from figure 3 , which plots the gains of $(1-L)^{d}$ for $d=0,0.25,0.359$, 0.5 , and 1 . Although all the fractional differencing operators with $d>0$ completely eliminate the zero frequency component, the filters differ greatly in terms of their gains over the finite frequencies, $0<\omega \leq \pi \cdot{ }^{30}$ The filter gain of $[2-2 \cdot \cos (\omega)]^{1 / 2}$ for the first difference operator, (1-L), associated with the Integrated GARCH, or IGARCH, class of models for $\sigma_{t}^{2}$, implies a much greater downweighting of the long-run dependencies than the fractional differencing filter with $d=0.359$.

The justfication, within the frequency domain, of filtering the five-minute DM- $\$$ absolute returns by $(1-L)^{0.359}$ is evident from the plot of the estimated spectrum for $(1-L)^{0.359}\left|R_{t}\right|$ given in

29 Both estimates are based on $m=168$ corresponding to a period of $3,648 / 168 \approx 21.7$ trading days, or approximately one month, along with $\ell=4$ and $q=0.25$.

30 Since the autocorrelations of a long-memory process with $d>0$ is not summable, all of the (1-L) filters necessarily eliminate the zero frequency component in order to achieve a bounded spectrum for the fractionally differenced series. 
figure $4 .^{31}$ The flat spectrum for $0<\omega<2 \cdot \pi / 288 \approx 0.0218$ reveals that the fractional differencing operator is, indeed, successful in eliminating the longer-run dependencies. At the same time, the pronounced peaks associated with the daily periodicity remain very similar across figures 1 and 4 . These results are further underscored by the time-domain autocorrelogram for $(1-L)^{0.359}\left|R_{1}\right|$ depicted in figure 5. Although more noisy, the autocorrelations exhibit the same repetitive daily cycles as the autocorrelations for the raw absolute returns in figure $2 .{ }^{32}$ However, in contrast to the autocorrelogram for the raw absolute returns, which display an overall slow hyperbolic rate of decay, the daily periodic patterns in the autocorrelogram for the fractionally differenced five-minute absolute returns are centered on zero. The long-run dependence in the series has been eliminated.

\section{LOW-PASS FILTERING AND LONG-RUN VOLATILITY DYNAMICS}

The frequency domain based estimators outlined in the previous section allow for the determination of the degree of long-run volatility dependence across the different sampling frequencies by explicitly focussing on the shape of the spectrum around the origin. Alternatively, a non-structural timedomain estimation procedure could be based on the eventual hyperbolic decay of the autocorrelation function implied by the presence of long-memory. However, as the sample autocorrelogram for the five-minute absolute returns in figure 2 clearly illustrates, the implementation of this idea is obscured by the strong intradaily periodicity. Various standardization procedures have previously been proposed for modeling the systematic intradaily patterns in the volatility of high frequency foreign exchange rates, including the time-deformation approach advocated by Müller et al. (1990) and Ghysels and Jasiak (1995), and the flexible Fourier functional form utilized by Andersen and Bollerslev (1996a, 1996b). ${ }^{33}$ These procedures are directly applicable in a forecasting context. In contrast, the low-pass filtering technique developed below is based on a two-sided weighted average of both past and future absolute returns. By explicitly annihilating the dependencies with a

31 The binomial expansion for (1-L) $)^{0.359}$ was truncated at a lag length of 1440 , corresponding to one week. Also, following Baillie, Bollerslev and Mikkelsen (1996) all of the pre-sample values for $\left|R_{Y}\right|$ were fixed at their unconditional sample analogues.

32 Note that the scales for the two autocorrelograms differ across figures 2 and 5. Also, the first order sample autocorrelation of -0.160 for $(1-\mathrm{L})^{0.359}\left|\mathrm{R}_{\mathrm{t}}\right|$ does not fit on the scale in figure 5 .

33 The notion of time deformation also underlies the motivation behind the Autoregressive Conditional Duration model in Engle and Russell (1996). 
periodicity of less than one day, the in-sample low-pass filtered absolute returns are designed to be void of any short-run intradaily dynamics, and as such provide a framework for the ex-post analysis of the long-run volatility determinants based on conventional time-domain methods.

Restricting the attention to daily and longer run dynamics, the ideal low-pass filter would have a gain, or a frequency response function, of zero for all of the intradaily frequencies, and a gain of unity for the interdaily frequencies; i.e., $\beta(\omega)=1$ for $0 \leq \omega<\omega_{D}$ and $\beta(\omega)=0$ for $\omega_{D} \leq \omega$ $\leq \pi$, where $\omega_{D}$ denotes the daily frequency. ${ }^{34}$ By standard filter theory the weights in the corresponding infinite two-sided time-domain filter, $b_{\infty}(L)=\Sigma_{j=-\infty}^{\infty} b_{\infty, j} L^{j}$, is readily found by the inverse Fourier transform; i.e., $b_{\infty, j}=\int_{0}^{\pi} \beta(\omega) \cdot \exp (i \cdot \omega \cdot j) d \omega=\sin \left(j \cdot \omega_{D}\right) /(j \cdot \pi)$ for $j \neq 0$ and $b_{\infty, 0}$ $=\int_{0}^{\pi} \beta(\omega) \mathrm{d} \omega=\omega_{\mathrm{D}} / \pi$. Of course, in practice, with a finite number of data points, this infinite filter is not applicable. However, the weights in the finite dimensional two-sided approximate filter,

$$
b_{p}(L)=\Sigma_{j=-p}^{p} b_{p, j} L^{j}
$$

that achieves the minimum squared approximation error, subject to the constraint that the filter weights sum to unity, is given by $b_{p, j}=b_{\infty, j}-\left(b_{\infty, 0}+2 \cdot \Sigma_{h=1}^{p} b_{\infty, h}-1\right) /(2 \cdot p+1)$ for $j=-p,-p+1$, $\ldots$, p; see, e.g., Baxter and King (1995). ${ }^{35}$ Since the weights are symmetric, the gain of this approximate low-pass filter may be conveniently written as, ${ }^{36}$

$$
\left|b_{p}[\exp (i \cdot \omega)]\right|=b_{p, 0}+2 \cdot \Sigma_{j=l}^{p} b_{p, j} \cdot \cos (j \cdot \omega)
$$

The higher the value of $\mathrm{p}$, the more accurate this gain approximates the ideal gain of $\beta(\omega)$. Of course, in practice a tradeoff is necessarily called for in terms of the shape of the gain given by

34 In terms of the theoretical framework in section 3, this low-pass filter would effectively eliminate all of the spectral mass in $V_{t}$ with a periodicity of less than one day, along with any seasonal component $S_{t, s(t)}$ as defined in equation (13).

35 Formally, this set of weights minimizes the squared approximation error given by $\int_{0}^{\pi}\left[b_{n}(\exp (i \cdot \omega))-\beta(\omega)\right]^{2} d \omega$. The constraint that the weights sum to unity ensures that the long-run zero frequency behavior of the series is unaltered by the filtering.

36 The symmetry of the filter also guarantees that the phase is equal to zero across all frequencies; i.e., $\phi(\omega)=$ $\tan ^{-1}\left\{\operatorname{Im}\left[b_{\Gamma}(\exp (i \cdot \omega))\right] / \operatorname{Re}\left[b_{p}(\exp (i \cdot \omega))\right]\right\}=0$. Intuitively, $\phi(\omega) / \omega$ represents the amount by which the filter shifts the series back in time at frequency $\omega$; see e.g. Koopmans (1974) for a general discussion of linear filter theory. 
equation (24) and the number of observations that have to be sacrificed at the beginning and end of the sample in the implementation of $b_{p}(L)$.

For the five-minute returns analyzed here, we took $\omega_{D}=0.021$, corresponding to roughly 299 periods or close to 25 hours, along with $p=1440$, or one week. The corresponding filter weights, $\mathrm{p}_{-1440}, \mathrm{p}_{-1439}, \ldots, \mathrm{p}_{1440}$, are given in figure 6 . The accuracy afforded by this choice of $\mathrm{p}$ is illustrated in figure 7 , which graphs the gain of the ideal low-pass filter along with this two-sided approximation. The overall coherence between the gain of the two filters is generally very good. Only for the frequencies close to $\omega_{D}$ is there some evidence that the frequencies greater than $\omega_{D}$ do not receive a zero weight and that the frequency gains for $\omega<\omega_{D}$ are different from unity. Such "leakage" and "compression" is inevitable with a finite value of $p$.

The effectiveness of this approximate low-pass filter in eliminating the short-run intradaily volatility components is clearly seen from figure 8 . The estimated spectrum for the filtered fiveminute absolute returns, $b_{1440}(L)\left|R_{l}\right|$, where $t=1441,1442, \ldots, 73440$, has virtually no-mass at the frequencies higher than $\omega_{\mathrm{D}} \cdot{ }^{37}$ Of course, the log-linear relation for the interdaily frequencies, implied by the presence of long-memory, remains intact.

This long-run dependence is also evident in the autocorrelation function for the low-pass filtered absolute returns. In contrast to the overall decay of the autocorrelogram for the raw absolute returns in figure 2 , which is masked by the strong recurring daily pattern, the autocorrelation function for $b_{1440}(L)\left|R_{t}\right|$, depicted in figure 9, display a distinct hyperbolic rate of decay. ${ }^{38}$ The actual magnitude of the correlations have also increased substantially. Even out to lag 2,880, or ten days, the autocorrelations all remain above 0.2 . Matching the sample autocorrelations for the lowpass filtered absolute returns with the hyperbolic decay implied by the presence of long-memory thus provides an alternative time-domain procedure for estimating $d$.

In general, since the autocorrelations of a long-memory process are eventually all positive, it follows that, for large $\mathrm{j}$,

37 Due to the loss of one week of observations at the beginning and the end of the sample, the filtered time series consist of "only" $74,880-2 \cdot 1,440=72,000$ observations. Of course, the logarithmic scale in figure 7 may be slightly misleading as the spectrum is not identically equal to zero for $\dot{\omega}>\omega_{\mathrm{D}}$.

38 A similarly shaped autocorrelogram for twenty-minute absolute DM- $\$$ returns standardized by a measure of the degree of market activity, or "theta-time", has been reported by Dacorogna et al. (1993). 


$$
\ln \left(\rho_{\mathrm{j}}\right) \approx \ln (\mathrm{c})+(2 \cdot \mathrm{d}-1) \cdot \ln (\mathrm{j})
$$

where $\rho_{\mathrm{j}}$ denotes the $\mathrm{j}$ 'th order autocorrelation, and $\mathrm{c}$ is just a factor of proportionality. Replacing the autocorrelations by their sample analogues, $\hat{\rho}_{\mathrm{j}}$, therefore suggests the following least squares estimator,

$$
\hat{\mathrm{d}}_{\mathrm{AC}}=1 / 2+1 / 2 \cdot\left\{\Sigma_{j=r+1}^{r+n}\left[\ln (j)-\overline{\mathrm{j}}_{\mathrm{r}, \mathrm{n}}\right] \cdot \ln \left(\hat{\rho}_{\mathrm{j}}\right)\right\} \cdot\left\{\sum_{\mathrm{j}=\mathrm{r}+1}^{\mathrm{r}+\mathrm{n}}\left[\ln (\mathrm{j})-\overline{\mathrm{j}}_{\mathrm{r}, \mathrm{n}}\right]^{2}\right\}^{-1}
$$

where $\overline{\mathrm{j}}_{\mathrm{r}, \mathrm{n}} \equiv \mathrm{n}^{-1} \cdot \sum_{\mathrm{j}=\mathrm{r}+1}^{\mathrm{n}+\mathrm{n}} \ln (\mathrm{j})$, and $\mathrm{r} \rightarrow \infty$, but $\mathrm{r} / \mathrm{T} \rightarrow 0$. This semi-parametric time-domain estimator for the fractional degree of integration, proposed by Robinson (1994b), is closely related to the minimum distance estimators recently analyzed by Tieslau, Schmidt and Baillie (1996). No formal asymptotic distribution theory is yet available for the estimator in equation (26), although it seems likely that $\hat{\mathrm{d}}_{\mathrm{AC}}$ will be consistent under rather weak regularity conditions.

Applying this estimator to the sample autocorrelations for the low-pass filtered absolute returns, $\hat{\rho}\left(b_{1440}(L)\left|R_{t}\right|, j\right)$ for $j=5,6, \ldots, 2880$, yields $\hat{d}_{A C}=0.359$. This estimate is thus fully consistent with the results from the frequency based procedures reported in the previous section. It is furthermore evident from the plot in figure 9, that the implied hyperbolic rate of decay, $\mathrm{j}^{2 \cdot 0.359-1}$ $=\mathrm{j}^{-0.282}$, is in close accordance with the actual shape of the autocorrelogram. It is worth stressing that, due to the strong intradaily volatility patterns and the associated recurring negative sample autocorrelations at the half-day lags, this estimation procedure for determining the fractional order of integration simply is not applicable with the raw absolute returns. Only by explicitly eliminating the intradaily dependencies do the sample autocorrelations all become positive and the hyperbolic decay stand out clearly.

The low-pass filtered returns also set the stage for a more structural investigation of the determinants behind the important volatility components. A detailed analysis along these lines is beyond the scope of the present paper. ${ }^{39}$ However, to illustrate consider the announcement effects associated with the Employment report, the Bundesbank biweekly meeting, the Durable Goods figures, and the report on Business Inventories discussed in section 2 above. On estimating the

39 Investigations into the relationship among macroeconomic variables over the business cycle frequencies using analogous band-pass filtering techniques have recently been conducted by Baxter (1994) and King and Watson (1996). 
average increase in the absolute five-minute DM-\$ returns in the two-hours immediately following the announcements,

$$
\left|R_{t}\right|=\gamma+\gamma_{N} \cdot D_{N}(t)+\epsilon_{t},
$$

the four coefficient estimates for $\gamma_{N}$ with robust standard errors in parentheses are $0.0091(0.0052)$, $0.0133(0.0025), 0.0067(0.0032)$ and $0.0143(0.0023)$, respectively. ${ }^{40}$ Thus, the effect associated with the Employment report is not significant at the conventional five percent level, while the Durable Goods report is only marginally significant. Also, the figures on Business Inventories appear to be the most significant of the four "news" events. These estimates should be carefully interpreted, however, as the intradaily pattern is prone to obscure the fundamental relationships. In fact, on estimating the identical regressions, given by equation (27), for the low-pass filtered returns, $b_{1440}(L)\left|R_{t}\right|$, the four estimates for $\gamma_{N}$ are $0.0076(0.0005), 0.0078(0.0004), 0.0032(0.0004)$, and $-0.0005(0.0005)$, respectively. The t-statistics for the three former announcements are now all overwhelmingly significant, while the release of the new figures for Business Inventories have no apparent effect on the volatility once the intradaily patterns in the absolute returns are filtered out. ${ }^{41}$ These results demonstrate how the low-pass filtered absolute returns provide a valuable framework for the further study of the structural determinants behind financial market volatility clustering.

\section{CONCLUSION}

The temporal dependence in the volatility of speculative returns is of the utmost importance for the pricing and hedging of financial contracts. Yet, the empirical analysis of low frequency interdaily and high frequency intradaily returns have hitherto given rise to very different conclusions regarding the degree of volatility persistence for any particular asset. The mixture-of-distributions hypothesis

40 In order to be compatible with the results for the low-pass filtered retums, the estimates are based on observations $t=1441,1442, \ldots, 73440$, only.

41 These results are in line with the evidence reported in Andersen and Bollerslev (1996b) and Payne (1996), who rely on relatively complicated flexible Fourier functional forms in explicitly modeling the periodicity in the intradaily volatility. These studies also suggest that the announcement effects may be better approximated by the imposition of a declining weight structure, as opposed to the simplistic two-hour fixed weighting scheme in the naive regression in equation (27). Jones, Lamont and Lumsdaine (1996) also report evidence in favor of a significant increase in daily bond market volatility following the release of the Employment report. 
developed here provides a justification for these conflicting empirical findings by interpreting the volatility as resulting from the aggregation of numerous constituent component processes; some with very short-run decay rates and others possessing much longer-run dependencies. When analyzing intradaily returns the short-run components will tend to dominate the estimates obtained with traditional time series models, whereas for daily or longer-run return intervals the estimates will be driven by the more persistent components. However, under suitable conditions the aggregation of these multiple components implies, that the process for the volatility should exhibit the identical form of long-memory dependence irrespective of the sampling intervals. This proposition is confirmed by our empirical analysis, which also demonstrates that, by annihilating the intradaily dependencies in time series of intradaily returns, it is possible to uncover this inherent long-memory dependence in relatively short calendar time spans of high frequency data using simple correlation based procedures. As such the techniques discussed here set the stage for the development of improved long-run interdaily volatility forecasts based on the large samples of intradaily prices which have recently become available for a wide variety of different instruments. Only future research will reveal the extent to which these techniques will support the development of new and improved empirical pricing relationships.

\section{References}

Andersen, T.G. (1992), "Volatility," manuscript, Department of Finance, J.L. Kellogg Graduate School of Management, Northwestern University.

Andersen, T.G. (1994), "Stochastic Autoregressive Volatility: A Framework for Volatility Modeling," Mathematical Finance, 4, 75-102.

Andersen, T.G. (1996), "Return Volatility and Trading Volume: An Information Flow Interpretation of Stochastic Volatility," Journal of Finance, 51, 169-204.

Andersen, T.G. and T. Bollerslev (1996a), "Intraday Periodicity and Volatility Persistence in Financial Markets," forthcoming Journal of Empirical Finance.

Andersen, T.G. and T. Bollerslev (1996b), "DM-Dollar Volatility: Intraday Activity Patterns, Macroeconomic Announcements, and Longer Run Dependencies," manuscript, Department of Finance, J.L. Kellogg Graduate School of Management, Northwestern University.

Andersen, T.G. and J. Lund (1996), "Stochastic Volatility and Mean Drift in the Short Term Interest rate Diffusion: Sources of Steepness, Level and Curvature in the Yield Curve," manuscript, Department of Finance, J.L. Kellogg Graduate School of Management, Northwestern University. 
Baillie, R.T. (1996), "Long-Memory Processes and Fractional Integration in Econometrics, "Journal of Econometrics, 73, 5-59.

Baillie, R.T. and T. Bollerslev (1989), "The Message in Daily Exchange Rates: A Conditional Variance Tale," Journal of Business and Economic Statistics, 7, 297-305.

Baillie, R.T. and T. Bollerslev (1991), "Intra-Day and Inter-Market Volatility in Foreign Exchange Rates," Review of Economic Studies, 58, 565-585.

Baillie, R.T., T. Bollerslev, and H.O. Mikkelsen (1996), "Fractionally Integrated Generalized Autoregressive Conditional Heteroskedasticity," Journal of Econometrics, forthcoming.

Baxter, M. (1994), "Real Exchange Rates and Real Interest Differentials: Have We Missed the BusinessCycle Relationship?," Journal of Monetary Economics, 33, 5-37.

Baxter, M. and R.G. King (1995), "Measuring Business Cycles: Approximate Band-Pass Filters for Economic Time Series," manuscript, Department of Economics, University of Virginia.

Beran, J. (1994), Statistics for Long-Memory Processes. New York: Chapman and Hall.

Bollerslev, T., R.Y. Chou and K.F. Kroner (1992), "ARCH Modeling in Finance," Journal of Econometrics, 52, 5-59.

Bollerslev, T. and I. Domowitz (1993), "Trading Patterns and Prices in the Interbank Foreign Exchange Market," Journal of Finance, 48, 1421-1443.

Bollerslev, T., R.F. Engle (1993), "Common Persistence in Conditional Variances," Econometrica, 61, 166-187.

Bollerslev, T., and H.O. Mikkelsen (1996a), "Modelling and Pricing Long-Memory in Stock Market Volatility," Journal of Econometrics, 73, 151-184.

Bollerslev, T., and H.O. Mikkelsen (1996b), "Long-Term Equity Anticipation Securities and Stock Market Volatility Dynamics," manuscript, Department of Economics, University of Virginia.

Breidt, F.J., N. Crato, and P. de Lima (1995), "On the Detection and Estimation of Long Memory in Stochastic Volatility," manuscript, Department of Statistics, Iowa State University.

Clark, P.K. (1973), "A Subordinated Stochastic Process Model with Finite Variance for Speculative Prices" Econometrica, 41, 135-155.

Dacorogna, M.M., U.A. Müller, R.J. Nagler, R.B. Olsen and O.V. Pictet (1993), "A Geographical Model for the Daily and Weekly Seasonal Volatility in the Foreign Exchange Market," Journal of International Money and Finance, 12, 413-438.

Delgado, M.A. and P.M. Robinson (1993), "New Methods for the Analysis of Long Memory Time Series: Application to Spanish Inflation," Journal of Forecasting, 13, 97-107. 
Ding, Z. and C.W.J. Granger (1996), "Modeling Volatility Persistence of Speculative Returns: A New Approach," Journal of Econometrics, 73, 185-215.

Ding, Z., C.W.J. Granger, and R.F. Engle (1993), "A Long Memory Property of Stock Market Returns and a New Model," Journal of Empirical Finance, 1, 83-106.

Drost, F.C. and T.E. Nijman (1993), "Temporal Aggregation of GARCH Processes," Econometrica, $61,909-927$.

Eddelbüttel, D. and T.H. McCurdy (1996), "The Impact of News on Foreign Exchange Rates: Evidence from Very High Frequency Data," manuscript, Department of Economics, Queen's University.

Ederington, L.H. and J.H. Lee (1993), "How Markets Process Information: News Releases and Volatility," Journal of Finance, 48, 1161-1191.

Ederington, L.H. and J.H. Lee (1995a), "The Creation and Resolution of Market Uncertainty: The Impact of Macroeconomic Announcements on Implied Volatility," manuscript, Department of Finance, University of Oklahoma.

Ederington, L.H. and J.H. Lee (1995b), "Volatility Prediction: ARCH, Announcement, and Seasonality Effects," manuscript, Department of Finance, University of Oklahoma.

Engle, R.F. and T. Bollerslev (1986), "Modelling the Persistence of Conditional Variances," Econometric Reviews, 5, 1-50.

Engle, R.F. and G.G.L. Lee (1993), "A Permanent and Transitory Component Model of Stock Return Volatility," manuscript, Department of Economics, University of California at San Diego.

Engle, R.F. and J.R. Russell (1996), "Forecasting the Frequency of Changes in Quoted Foreign Exchange Prices with the ACD Model," Journal of Empirical Finance, forthcoming.

Epps, T.W. and M.L. Epps (1976), "The Stochastic Dependence of Security Price Changes and Transaction Volumes: Implications for the Mixture-of-Distributions Hypothesis, "Econometrica, 44, 305-321.

Gallant, A.R. and G.E. Tauchen (1996), "Which Moments to Match," Econometric Theory, forthcoming.

Gallant, A.R., D. Hsieh and G. Tauchen (1994), "Estimation of Stochastic Volatility Models with Diagnostics," manuscript, Department of Economics, Duke University.

Geweke, J. and S. Porter-Hudak (1983), "The Estimation and Application of Long-Memory Time Series Models," Journal of Time Series Analysis, 4, 221-238.

Ghose, D. and K.F. Kroner (1996), "Components of Volatility in Foreign Exchange Markets: An Empirical Analysis of High Frequency Data," manuscript, Department of Economics, University of Arizona. 
Ghysels, E., and J. Jasiak (1995), "Trading Patterns, Time Deformation and Stochastic Volatility in Foreign Exchange Markets," manuscript, Department of Economics, University of Montreal.

Goodhart, C.A.E., S.G. Hall, S.G.B. Henry and B. Pesaran (1993), "News Effects in a High-Frequency Model of the Sterling-Dollar Exchange Rate," Journal of Applied Econometrics, 8, 1-13.

Goodhart, C., T. Ito, and R. Payne (1996), "One Day in June 1993: A Study of the Working of Reuters' Dealing 2000-2 Electronic Foreign Exchange Trading System," in The Microstructure of Foreign Exchange Markets (J. Frankel, A. Galli and A. Giovannini, eds.), Chicago: University of Chicago Press.

Goodhart, C.A.E. and M. O'Hara (1996), "High Frequency Data in Financial Markets: Issues and Applications," forthcoming Journal of Empirical Finance.

Granger, C.W.J. (1980), "Long Memory Relationships and the Aggregation of Dynamic Models," Journal of Econometrics, 14, 227-238.

Granger, C.W.J. (1988), "Models that Generate Trends," Journal of Time Series Analysis, 9, 329-343.

Granger, C.W.J. (1987), "Generalized Integrated Processes," manuscript, Department of Economics, University of California, San Diego.

Granger, C.W.J. and Z. Ding (1996a), "Varieties of Long Memory Models, "Journal of Econometrics, $73,61-77$.

Granger, C.W.J. and Z. Ding (1996b), "Some Properties of Absolute Return: An Alternative Measure of Risk," Annales d'Economie et de Statistique, forthcoming.

Granger, C.W.J. and P. Newbold (1976), "Forecasting Transformed Series," Journal of the Royal Statistical Soceity, Series B, 38, 189-203.

Guillaume, D.M., O.V. Pictet and M.M. Dacorogna (1995), "On the Intradaily Performance of GARCH Processes," manuscript, Olsen \& Associates, Research Institute for Applied Economics, Zürich, Switzerland.

Hamilton, J.D. (1994), Time Series Analysis. Princeton: Princeton University Press.

Harris, L. (1986) "A Transaction Data Study of Weekly and Intradaily Patterns in Stock Returns," Journal of Financial Economics, 16, 99-117.

Harris, L. (1987), "Transaction Data Tests of the Mixture of Distributions Hypothesis," Journal of Financial and Quantitative Analysis, 22, 127-141.

Harvey, A.C. (1994), "Long-Memory in Stochastic Volatility," manuscript, London School of Economics. 
Harvey, A.C. and M. Streibel (1996), "Testing for a Slowly Changing Level with Special Reference to Stochastic Volatility," manuscript, London School of Economics.

Harvey, C.R. and R.D. Huang (1991), "Volatility in the Foreign Currency Futures Market, " Review of Financial Studies, 4, 543-569.

Hogan, Jr., K.C. and M.T. Melvin (1994), "Sources of Heat Waves and Meteor Showers in the Foreign Exchange Markets," Journal of International Economics, 37, 239-247.

Hsieh, D.A. (1989), "Modeling Heteroskedasticity in Daily Foreign Exchange Rates," Journal of Business and Economic Statistics, 7, 307-317.

Ito, T., V.V. Roley (1987), "News from the U.S. and Japan: Which Moves the Yen/Dollar Exchange Rate?," Journal of Monetary Economics, 19, 255-277.

Ito, T., R.K. Lyons and M.T. Melvin (1996), "Is There Private Information in the FX Market? The Tokyo Experiment," manuscript, Haas School of Business, University of California at Berkeley.

Jacquier, E., N.G. Polson and P.E. Rossi (1994), "Bayesian Analysis of Stochastic Volatility Models," Journal of Business and Economic Statistics, 12, 371-417.

Johnson, N.L. and S. Kotz (1970), Continuous Univariate Distributions - 2. New York: John Wiley and Sons.

Jones, C., O. Lamont and R. Lumsdaine (1996), "Public Information and the Persistence of Bond Market Volatility," manuscript, Department of Economics, Princeton University.

King, R.G. and M. W. Watson (1996) "Money, Prices, Interest Rates and the Business Cycle," Review of Economics and Statistics, 78, 35-53.

Koopmans, L. (1974, The Spectral Analysis of Time Series. New York: Academic Press.

Lamoureux, C.G. and W.D. Lastrapes (1990) "Persistence in Variance, Structural Change and the GARCH Model," Journal of Business and Economic Statistics, 8, 225-234.

Lin, J.-L. (1991), "Generalized Integrated Processes and the Aggregation of Dynamic Time Series," Academia Economic Papers, 19, 207-226.

Liu, M. (1995), "Modeling Long-Memory in Stock Market Volatility," manuscript, Department of Economics, Duke University.

Lobato, I. and P.M. Robinson (1996) "Averaged Periodogram Estimation of Long-Memory," Journal of Econometrics, 73, 303-324.

Mandelbrot, B.B. (1971), "A Fast Fractional Gaussian Noise Generator," Water Resources Research, 7, 543-553. 
Mandelbrot, B.B. and J.R. Wallis (1969), "Computer Experiments with Fractional Gaussian Noises," Water Resources Research, 5, 321-340.

Mandelbrot, B.B. and J.W. van Ness (1968), "Fractional Brownian Motions, Fractional Noises and Applications," SIAM Review, 10, 422-437.

McCurdy, T.H. and P.K. Michaud (1996), "Capturing Long Memory in the Volatility of Equity Returns: A Fractionally Integrated Asymmetric Power ARCH Model, " manuscript, Department of Economics, Queen's University.

Müller, U.A., M.M. Dacorogna, R.B. Olsen, O.V. Pictet, M. Schwarz and C. Morgenegg (1990), "Statistical Study of Foreign Exchange Rates, Empirical Evidence of a Price Change Scaling Law, and Intraday Analysis," Journal of Banking of Finance, 14, 1189-1208.

Müller, U.A., M.M. Dacorogna, R.D. Davé, O.V. Pictet, R.B. Olsen, and J.R. Ward (1993), "Fractals and Intrinsic Time - A Challenge to Econometricians," manuscript, Olsen \& Associates, Research Institute for Applied Economics, Zürich, Switzerland.

Müller, U.A., M.M. Dacorogna, R.D. Davé, R.B. Olsen, O.V. Pictet, and J.E. von Weizsäcker (1995), "Volatilities of Different Time Resolutions - Analyzing the Dynamics of Market Components," manuscript, Olsen \& Associates, Research Institute for Applied Economics, Zürich, Switzerland.

Nelson, D.B. (1990), "ARCH Models as Diffusion Approximations," Journal of Econometrics, 45, 738.

Nelson, D.B. (1992), "Filtering and Forecasting with Misspecified ARCH Models I: Getting the Right Variance with the Wrong Model," Journal of Econometrics, 52, 61-90.

Palm, F.C. and J.-P. Urbain (1995), "Common Trends and Transitory Components of Stock Price Volatility," manuscript, Department of Economics, University of Limburg.

Payne, R. (1996) "Announcement Effects and Seasonality in the Intraday Foreign Exchange Market," manuscript, Financial Markets Group, London School of Economics.

Priestley, M.B. (1981), Spectral Analysis and Time Series. London: Academic Press.

Robinson, P.M. (1994a), "Semiparametric Analysis of Long-Memory Time Series," Annals of Statistics, $22,515-539$.

Robinson, P.M. (1994b), "Time Series with Strong Dependence," in Advances in Econometrics: Sixth World Congress Vol.1 (C.A. Sims, ed.), Cambridge: Cambridge University Press.

Robinson, P.M. (1995), "Log-Periodogram Regression of Time Series with Long-Range Dependence," Annals of Statistics, 23, 1048-1072.

Ross, S.A. (1976), "The Arbitrage Theory of Capital Asset Pricing," Journal of Economic Theory, 13, 341-360. 
Ross, S.A. (1989), "Information and Volatility: The No-Arbitrage Martingale Approach to Timing and Resolution Irrelevancy," Journal of Finance, 44, 1-18.

Shephard, N. (1996), "Statistical Aspects of ARCH and Stochastic Volatility," in Likelihood, Time Series with Econometric and Other Applications (D.R. Cox, D.V. Hinkley and O.E. Barndorff-Nielsen, eds.), London, UK: Chapman and Hall.

Tauchen, G.E. and M. Pitts (1983) "The Price Variability-Volume Relationship on Speculative Markets," Econometrica, 51, 485-505.

Taylor, S.J. (1994) "Modelling Stochastic Volatility," Mathematical Finance, 4, 183-204.

Theil, H. (1954), Linear Aggregation of Economic Relations. Amsterdam: North Holland.

Tieslau, M.A., P. Schmidt and R.T. Baillie (1996), "A Minimum Distance Estimator for Long-Memory Processes," Journal of Econometrics, 71, 249-264.

Wood, R.A., T.H. McInish and J.K. Ord (1985), "An Investigation of Transaction Data for NYSE Stocks," Journal of Finance, 25, 723-739. 


\section{Table I}

Persistence Measures for Temporally Aggregated Absolute Intraday Returns

\begin{tabular}{|c|c|c|c|c|}
\hline $\mathrm{k}$ & $\mathrm{T} / \mathrm{k}$ & $\hat{\rho}^{(\mathbf{k})}$ & $\hat{\mathrm{d}}_{\mathrm{GH}}^{(\mathrm{k})}$ & $\hat{\mathrm{d}}_{\mathrm{AP}}^{(\mathrm{k})}$ \\
\hline 1 & 74,880 & 0.309 & 0.321 & 0.385 \\
\hline 2 & 37,440 & 0.313 & 0.367 & 0.375 \\
\hline 3 & 24,960 & 0.307 & 0.337 & 0.376 \\
\hline 4 & 18,720 & 0.287 & 0.339 & 0.364 \\
\hline 6 & 12,480 & 0.268 & 0.288 & 0.351 \\
\hline 8 & 9,360 & 0.272 & 0.281 & 0.340 \\
\hline 9 & 8,320 & 0.251 & 0.214 & 0.333 \\
\hline 12 & 6,240 & 0.229 & 0.309 & 0.317 \\
\hline 16 & 4,680 & 0.246 & 0.269 & 0.303 \\
\hline 18 & 4,160 & 0.193 & 0.457 & 0.310 \\
\hline 24 & 3,120 & 0.164 & 0.220 & 0.291 \\
\hline 32 & 2,340 & 0.171 & 0.221 & 0.302 \\
\hline 36 & 2,080 & 0.097 & 0.178 & 0.275 \\
\hline 48 & 1,560 & 0.075 & 0.236 & 0.311 \\
\hline 72 & 1,040 & 0.007 & 0.214 & 0.270 \\
\hline 96 & 780 & -0.025 & 0.382 & 0.274 \\
\hline 144 & 520 & -0.033 & 0.382 & 0.286 \\
\hline
\end{tabular}

Notes: The percentage returns are based on interpolated 5-minute logarithmic average bid-ask quotes for the Deutschemark - U.S. Dollar spot exchange rate from October 1, 1992 through September 29, 1993. Quotes from Friday 21:00 Greenwich Mean Time (GMT) through Sunday 21:00 GMT have been excluded, resulting in a total of 74,880 5-minute return observations. The length of the different intraday sampling intervals equal $5 \cdot \mathrm{k}$ minutes. Each absolute return series consists of a total of 74,880 /k non-overlapping observations; i.e., $\left|R_{r}^{(\mathrm{k})}\right|$ $\equiv\left|\mathbf{R}_{\tau \cdot \mathbf{k}}+\mathbf{R}_{r \cdot k-1}+\ldots \mathbf{R}_{r \cdot k \cdot k+1}\right|$ where $\tau=1,2, \ldots, T / k$ and $T=74,880$. The $\hat{\rho}^{(k)}$ column gives the first order autocorrelations for $\left|R_{r}^{(k)}\right|$. The Log-Periodogram estimates for $\mathbf{d}$ from equation (18) are denoted by $\hat{d}_{G \mathrm{H}}^{(k)}$. The truncation and trimming parameters for $k=2,3, \ldots$, 144 are determined by $\mathrm{m}=\left[(\mathrm{T} / \mathrm{k})^{1 / 2}\right]$ and $\ell=\left[\mathrm{m}^{1 / 4}\right]$, respectively, where $[\cdot]$ denotes the integer value. In order to avoid any confounding effects from frequencies corresponding to less than one day, the estimate for $\hat{\mathrm{d}}_{\mathrm{GH}}^{(1)}$ is based on $\mathrm{m}=255$ and $\ell=3$. The $\hat{\mathrm{d}}_{\mathrm{AP}}^{(\mathrm{k})}$ column gives the average periodogram estimates for $d$ defined in equation (21). The truncation parameters are determined by $m=\left[(T / k)^{1 / 2}\right]$ for $k=2,3, \ldots, 144$, while $\hat{d}_{A P}^{(1)}$ is based on $m$ $=255$. The scalar $q$ is fixed at $1 / 4$ across all sampling frequencies. 


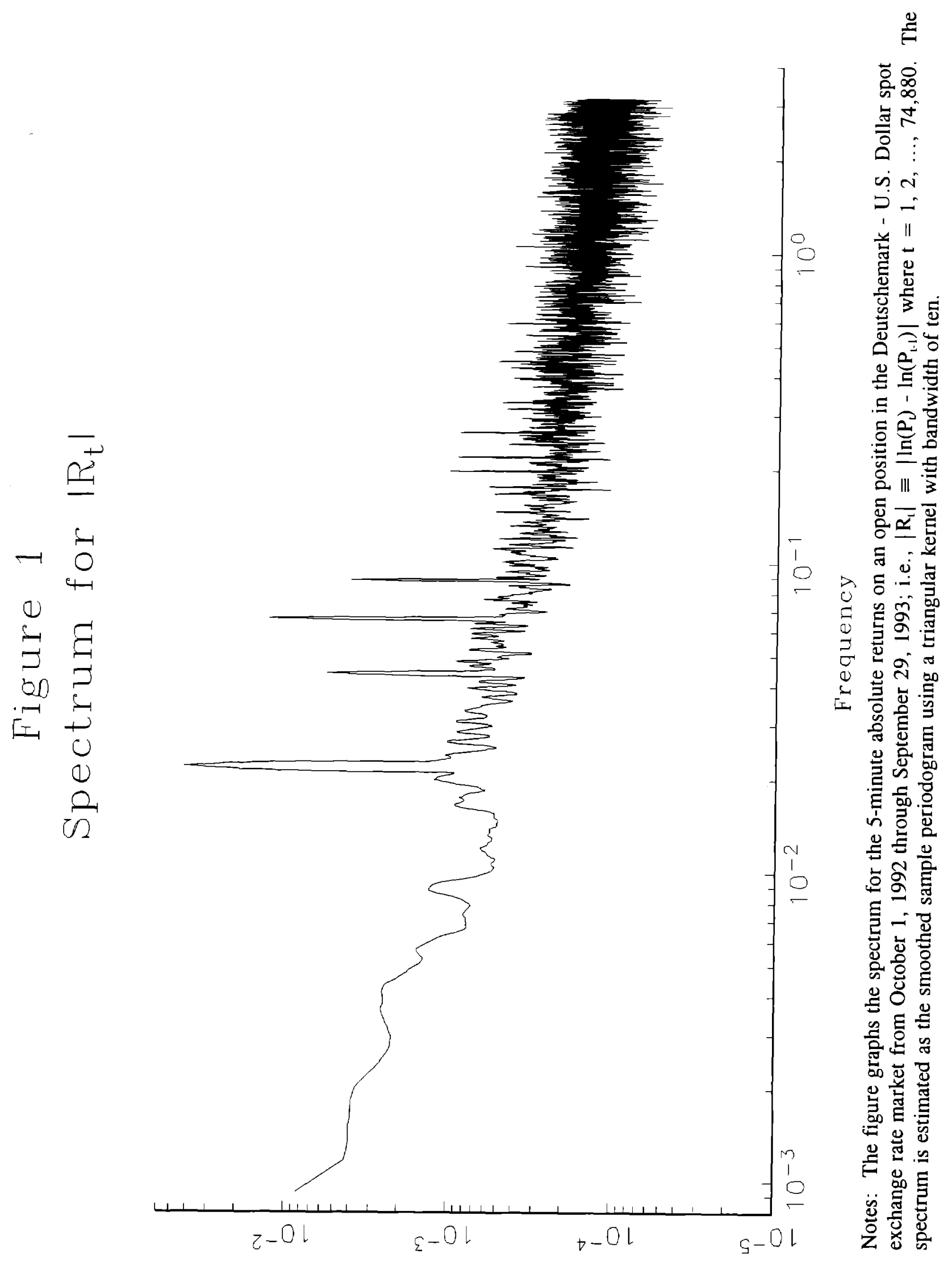



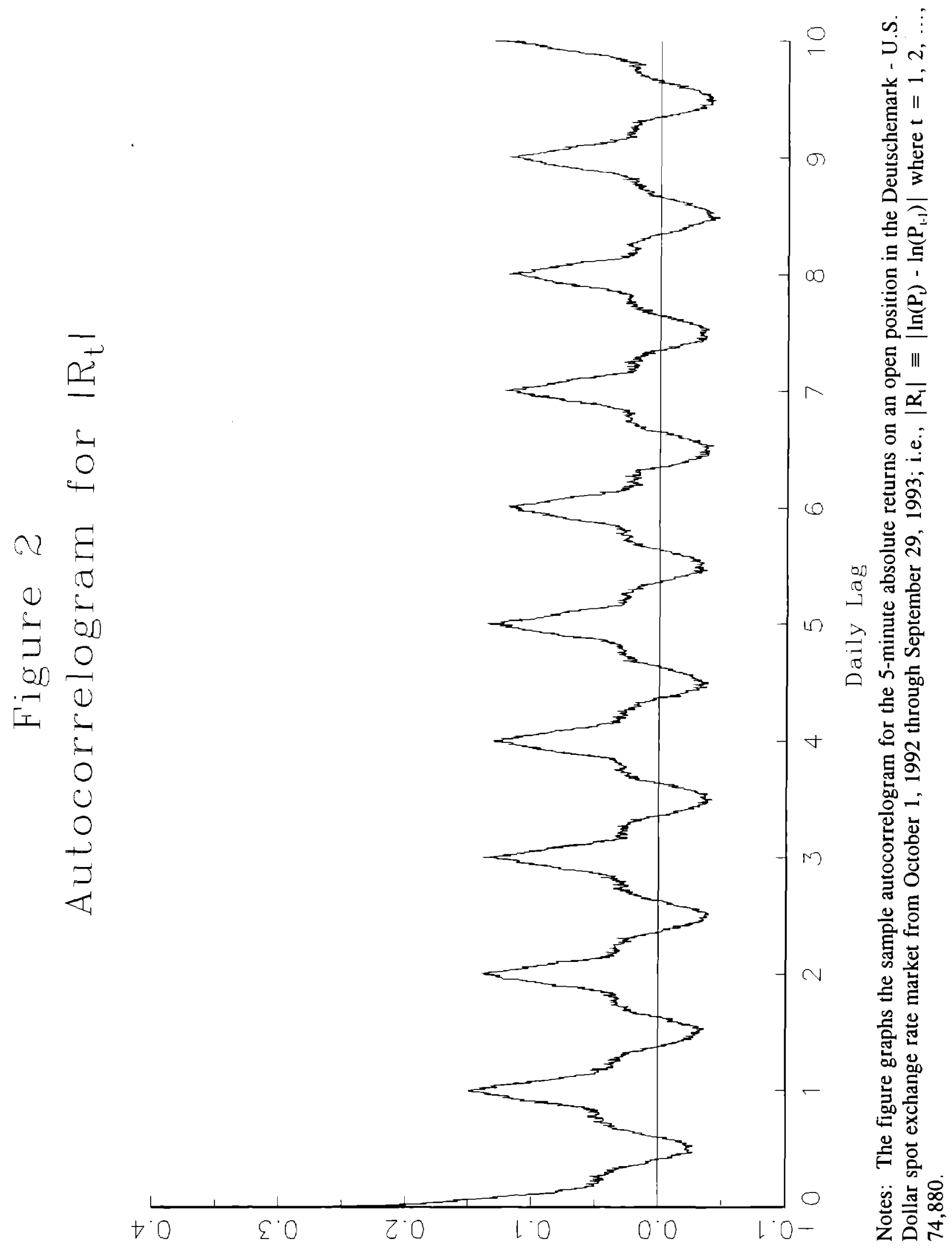


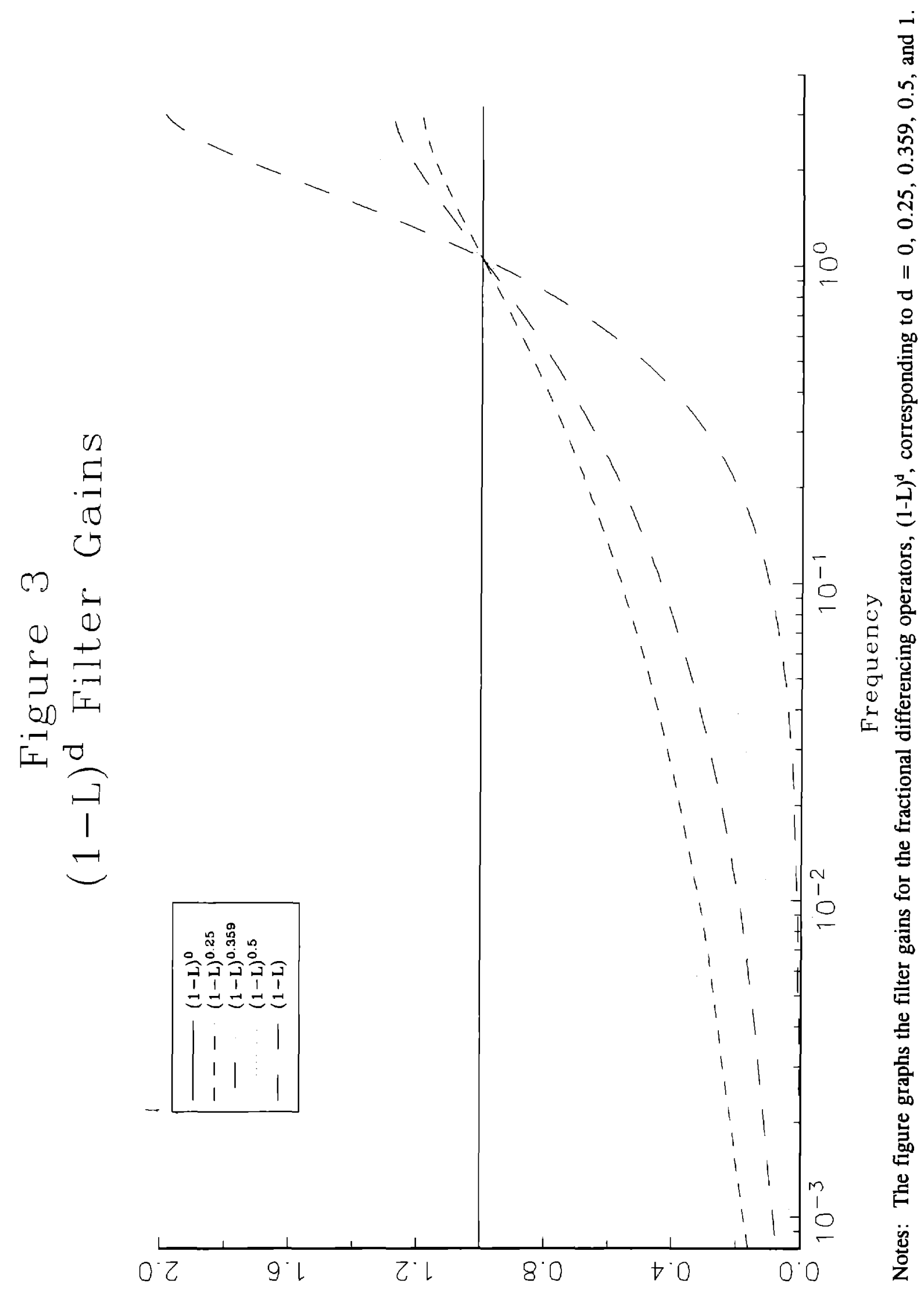



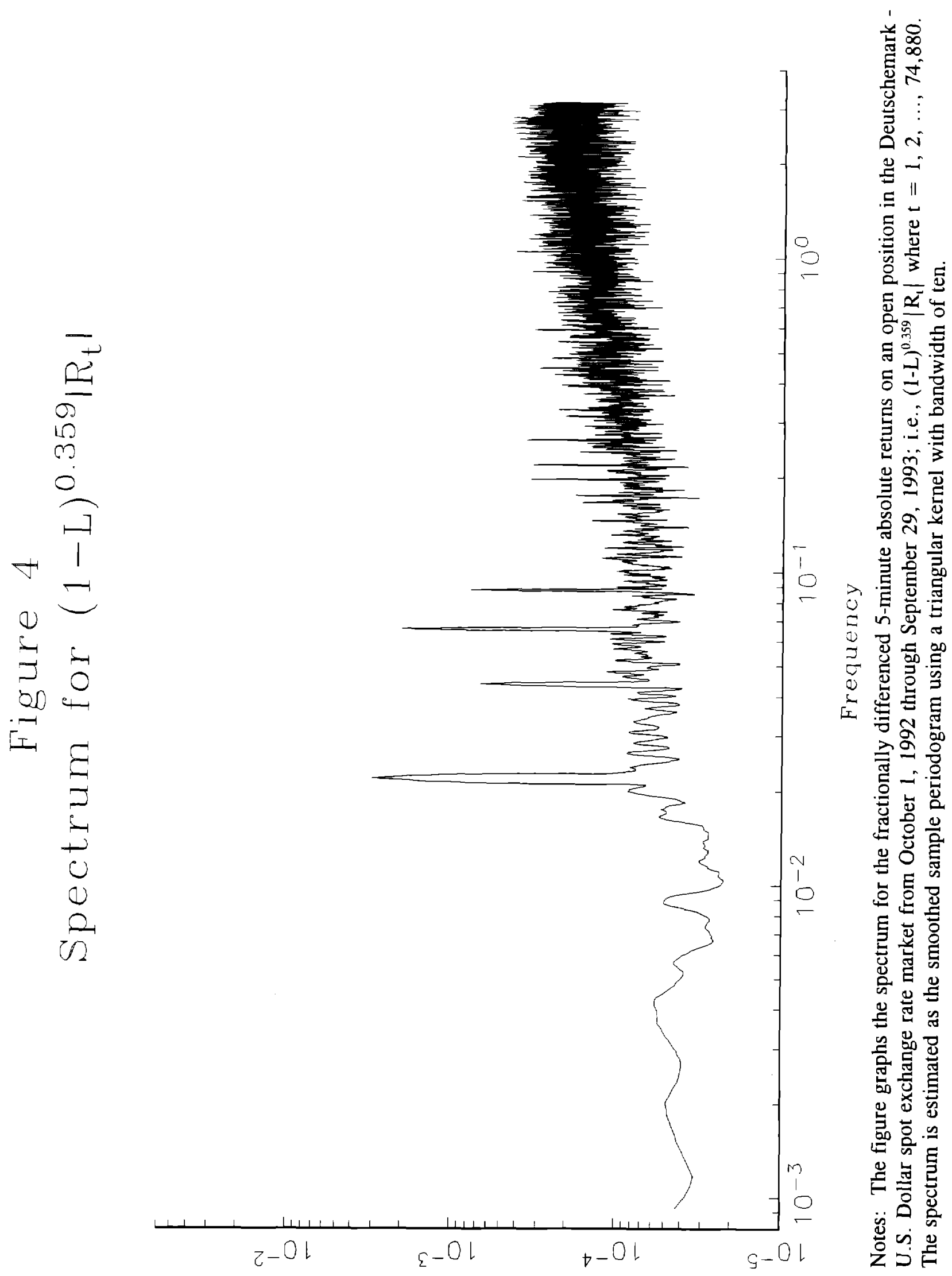

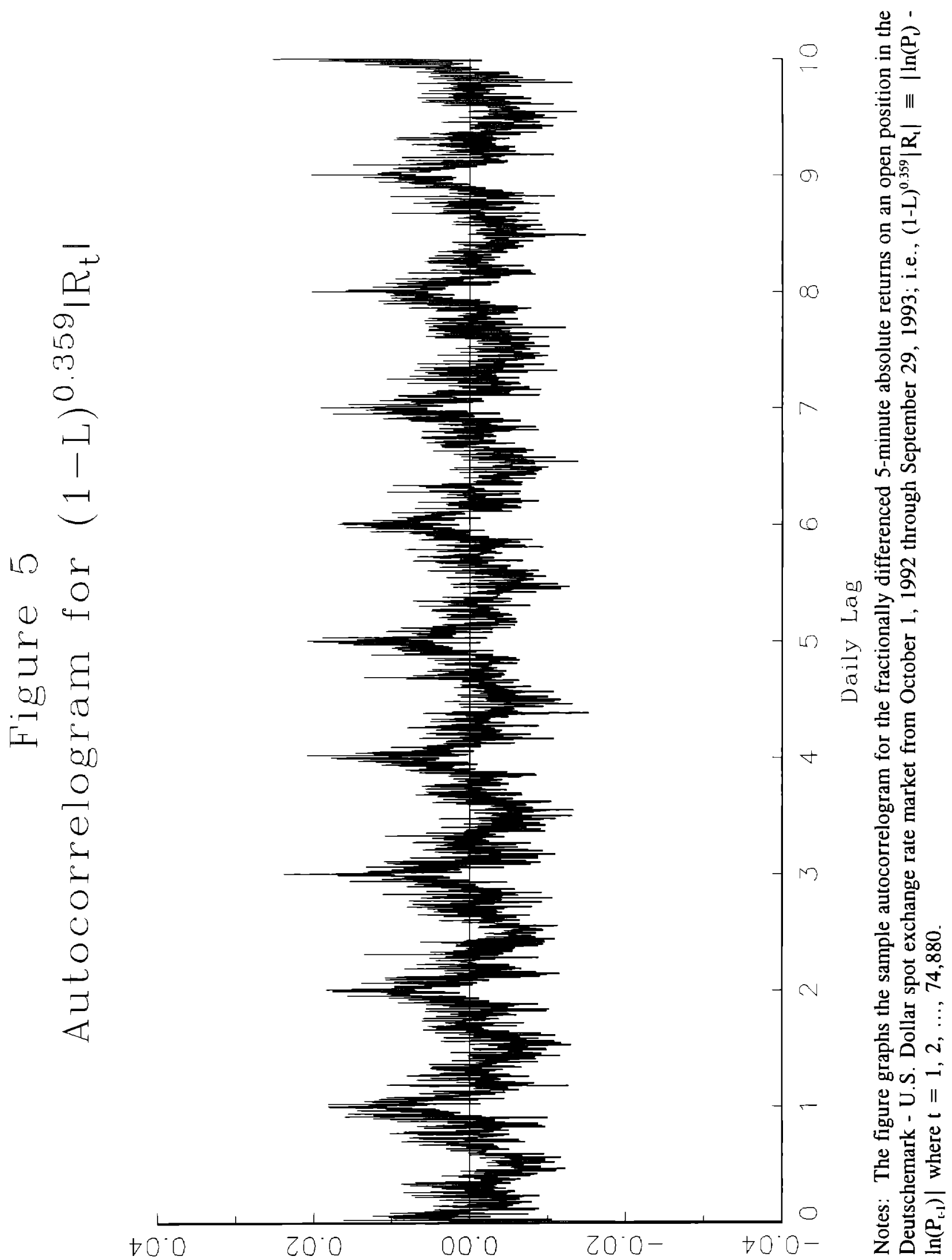


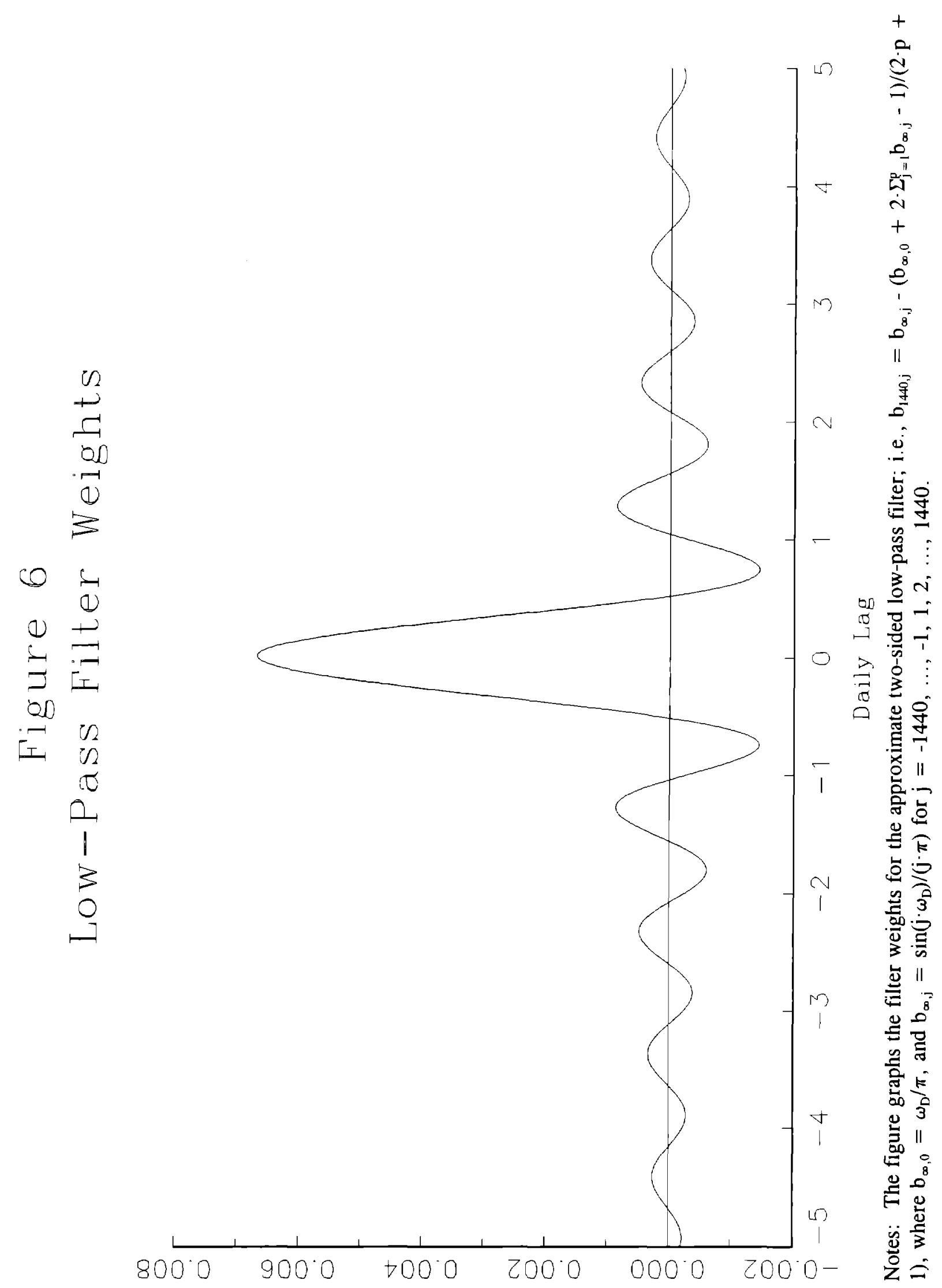




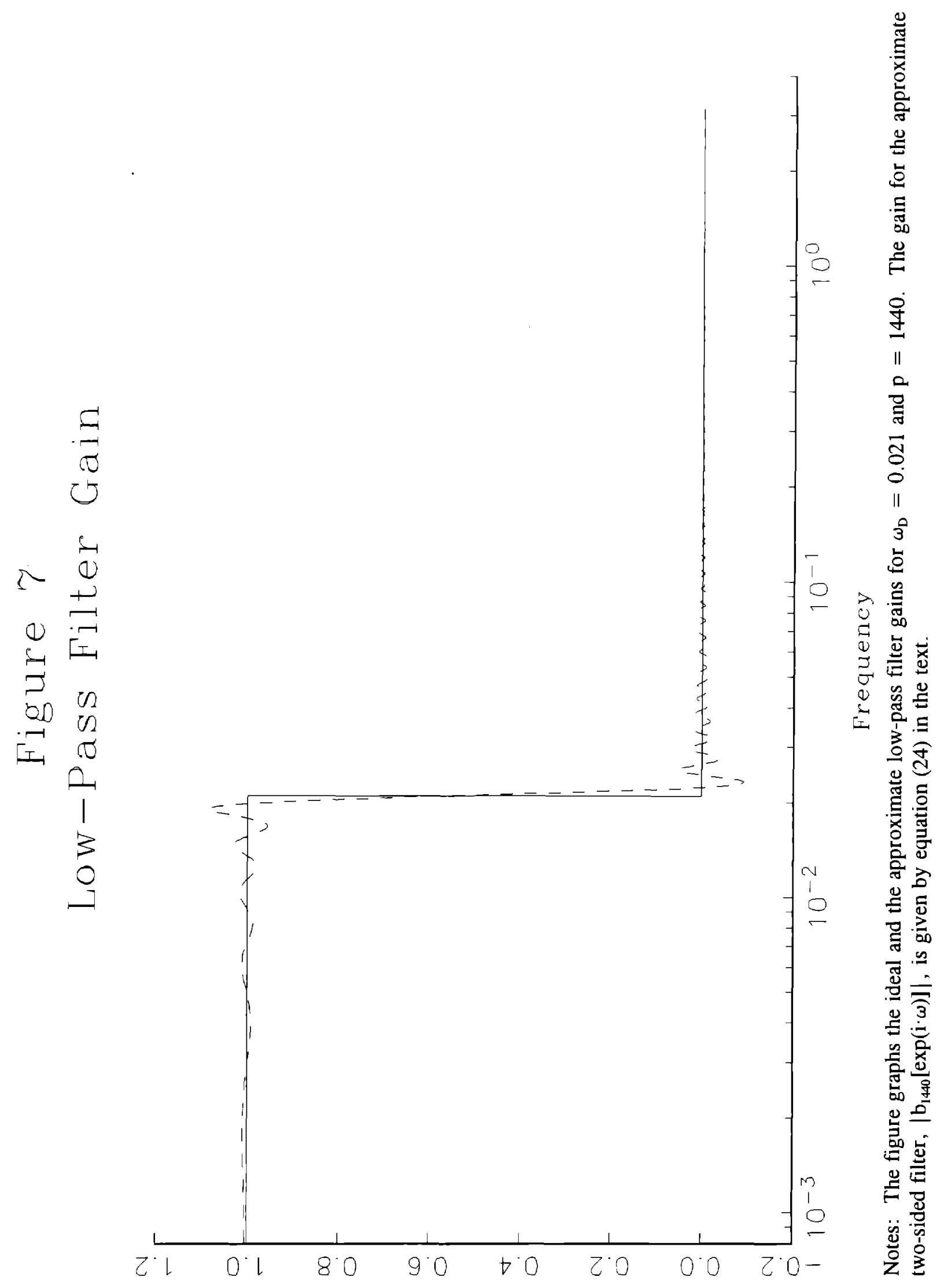




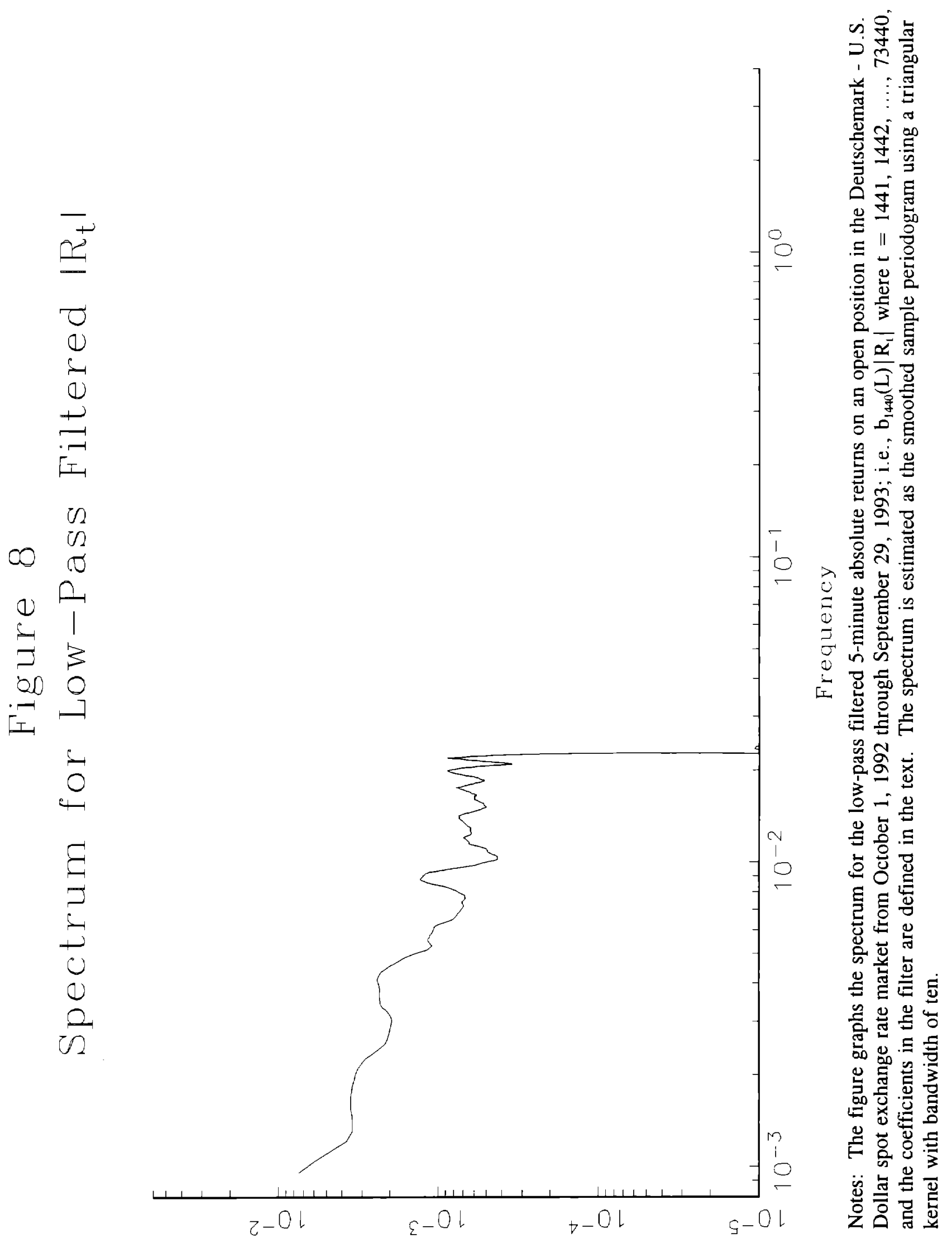




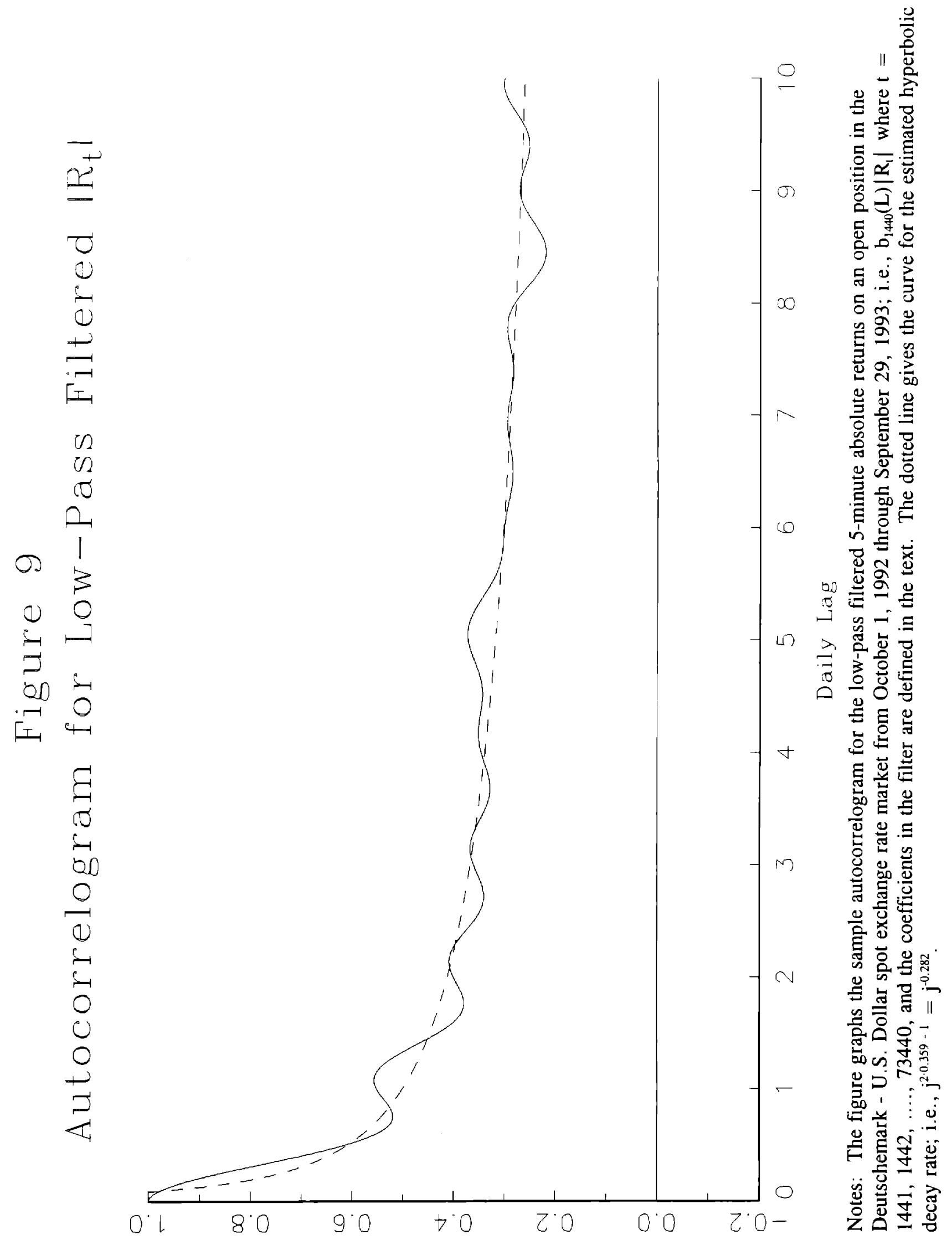

